\title{
Aglomeração Industrial no Brasil: Um Estudo Empírico
}

\author{
Marcelo Resende \\ Ricardo Wyllie
}

Instituto de Economia, Universidade Federal do Rio de Janeiro

Fundação Getulio Vargas

\begin{abstract}
RESUMO
O artigo mede a aglomeração industrial para a indústria de transformação no Brasil em 1995 e 2001. Consideram-se medidas recentemente desenvolvidas por Ellison e Glaeser (1997), Maurel e Sédillot (1999) e Devereux et al. (2004) que se amparam em microdados e que possuem sólido fundamento teórico. A evidência indicou que uma substancial heterogeneidade estava presente entre os diferentes setores. Entre os líderes existem setores com conteúdos tecnológicos bastante distintos que apenas parcialmente coincidem com os encontrados na França e no Reino Unido. Adicionalmente, pode-se observar mudanças substanciais nos padrões de aglomeração industrial entre 1995 e 2001.
\end{abstract}

\section{PALAVRAS-CHAVE}

aglomeração industrial, concentração

ABSTRACT

The article measures industrial agglomeration in the Brazilian manufacturing industry in 1995 and 200I. It considers measures that were recently developed by Ellison and Glaeser (1997), Maurel and Sédillot (1999) and Devereux et al. (2004) that rely in microdata and are theoretically sound. The evidence indicated that a substantial heterogeneity was present across the different sectors. Among the leaders there are sectors with very different technological content that only partially coincide with the leading sectors in France and United Kingdom. Moreover, one can observe substantial changes in the agglomeration patterns between 1995 and 2001.

KEY WORDS industrial agglomeration, concentration

JEL Classification

$L I / O, R / 20$ 


\section{INTRODUÇÃO}

A desigualdade entre diferentes países tem constituído um tema recorrente na literatura de Desenvolvimento Econômico (ver, por exemplo, KRUGMAN \& VENABLES, 1995 e DURO-MORENO, 2001). Um interesse similar tem se manifestado em termos da investigação de desigualdades regionais dentro dos diferentes países e no Brasil em particular (ver FERREIRA \& ELLERY, 1996 e AZZONI, 1997). Com efeito, a consolidação da chamada Ciência Regional (Regional Science) está amplamente associada a tais questóes na medida em que fornece um arcabouço conceitual para fatores locacionais da atividade econômica (ver ISARD, 1956, 1960). Em economias de grande porte e elevada heterogeneidade como a brasileira, o diagnóstico de padrões regionais de localização da atividade econômica reveste-se de especial interesse como orientador potencial de políticas locais explícitas que visem atenuar os desequilíbrios regionais.

O renovado interesse em questões regionais em trabalhos influentes como os de Krugman (1991) indicam que pode haver condicionantes de natureza histórica para a localização que ultrapassam aspectos puramente associados às externalidades. No tocante a esses últimos determinantes das aglomerações econômicas deve ser mencionada a classificação sugerida por Hoover (1936) (apud MAUREL \& SÉDILLOT, 1999), que define dois tipos de externalidades. O primeiro tipo refere-se às chamadas economias de localização, que beneficiam firmas que sejam da mesma indústria, definindo um fator explicativo de aglomeração que é específico do setor de atividade considerado. $\mathrm{O}$ segundo tipo refere-se às economias de urbanização capazes de beneficiar indistintamente firmas de diferentes indústrias que estejam concentradas em uma determinada localidade. Adicionalmente, e funcionando como uma espécie de sintetizador para os fatores de concentração, segue-se o conceito de eficiência coletiva capaz de agregar determinantes relativos às forças naturais de mercado, à iteração local entre os agentes, bem como destes com o setor público (ver, por exemplo, ALTENBURG \& MEYERSTAMER, 1999). A forma específica como esses e outros diferentes itens se articulam para determinar aglomeraçốes da atividade econômica definem os diferentes paradigmas prevalecentes e implicam escopos diferenciados para políticas, públicas e privadas, que se pretendam ativas no desenvolvimento regional. ${ }^{1}$ Pode-se afirmar, em última instância, que o amplo interesse no estudo da aglomeração relaciona-se ao efeito que essa pode ter sobre a produtividade (ver ROSENTHAL \& STRANGE, 2001).

Deve-se salientar que a investigação dos determinantes da aglomeração industrial assim como a relação desta com movimentos da produtividade extrapolam o escopo do presente trabalho.

1 Na seção 2 discutem-se as principais vertentes teóricas relevantes para o estudo da localização industrial, e vale mencionar que DINIZ (2001) fornece um sumário da evolução das políticas de desenvolvimento regional no Brasil. 
A literatura brasileira que trata de questóes regionais pode ser dividida, como uma primeira aproximação, em duas vertentes básicas: aquela que privilegia como condicionantes os históricos nas estruturas econômicas em regiões específicas (ver CANO, 1977, 1985) e uma segunda vertente que chama para si as motivações mais caras às linhas de pesquisa investigadas nas economias mais desenvolvidas. Essa última envolve esforços qualitativos e freqüentemente quantitativos abrangendo estudos de concentração regional (ver HADDAD, 1989). Merecem destaque, em particular, estudos mais recentes acerca da concentração espacial que focalizam aspectos mais quantitativos da localização da atividade econômica como Diniz e Crocco (1996), Pacheco (1999), Andrade e Serra (2000), Saboia (2000) e Suzigan et al. (2001). Os aspectos teóricos e conceituais discutidos por estes autores são apropriados no sentido de explicitar as estruturas de aglomerações, e respectivas motivações, que podem ser encontradas na prática. Contudo, em relação ao aspecto empírico, a totalidade dos estudos empreendidos para o Brasil está focalizada em indicadores construídos a partir de dados mais agregados, recorrendo-se freqüentemente a estudos de caso em localidades específicas. Permanece, assim, uma importante lacuna na literatura nacional no que concerne a um diagnóstico mais pormenorizado acerca do fenômeno da aglomeração industrial. Nesse sentido, o presente trabalho pretende explorar tal lacuna a partir de indicadores de aglomeração industrial recentemente propostos na literatura que permitem uma caracterização mais apropriada do fenômeno da aglomeração industrial. De fato, o primeiro passo para estudos mais aprofundados e delineamento de políticas é o da construção de medidas conceitualmente sólidas, ora viabilizadas por bases de dados e modelos mais sofisticados.

O trabalho está organizado da seguinte forma. A seção a seguir discorre sobre os estudos empíricos mais recentes de localização industrial no Brasil. A segunda seção apresenta os aspectos metodológicos necessários para a análise, que incluem digressôes acerca de medidas de aglomeração. Na terceira seção é dedicada à descrição e comentários sobre a base de dados a ser utilizada, com ênfase na eficiência relativa e nas limitaçôes que possui. A quarta seção apresenta e discute os resultados empíricos. A última seção apresenta os comentários finais e sugestões para pesquisas futuras.

\section{LOCALIZAÇÃO INDUSTRIAL: ESTUDOS EMPÍRICOS PARA O BRASIL}

O interesse acadêmico sobre a questão da concentração industrial da indústria no Brasil tem suscitado diferentes estudos recentes de cunho quantitativo, sobre os quais faremos breve exposição. ${ }^{2}$

2 Para uma discussão dos marcos conceituais associados à questão da aglomeração industrial ver SUZIGAN (2001), SUZIGAN et al. (2001) e SCHMIDT (1999). 
Diniz e Crocco (1996) utilizaram os censos industriais do IBGE para 1970 e 1985, o censo demográfico de 1991, além de dados da Relação Anual de Informações SociaisRAIS (Ministério do Trabalho). Empregaram como indicador de concentração para diferentes unidades espaciais (grandes regiões, estados e áreas com mais de 10.000 pessoas empregadas na indústria-AIR) medidas construídas a partir do valor da transformação industrial e do nível de emprego em termos de participações porcentuais. Merecem destaque os processos de desconcentração da atividade industrial quando consideradas as grandes regiões, principais estados e regióes metropolitanas. O processo inicia-se pela perda de participação da região Sudeste, sobretudo relativamente aos estados do Sul e ainda a Bahia. Quando se consideram dados mais desagregados em termos das AIR, evidencia-se um processo de reconcentração em áreas específicas, onde o crescimento do emprego mostrou-se mais acelerado.

Azzoni (1997) utiliza dados do IBGE do Censo Industrial de 1985 para obter medidas de produtividade da mão-de-obra em termos regionais. Considerando a participação dos setores nas regiôes, o autor determina qual seria o produto agregado caso a produtividade, de cada setor, fosse igual à média nacional. Uma comparação entre esta última estatística e o efetivo valor da produção (apurado pelo valor da transformação industrial) revela, segundo o autor, um diferencial de produtividade que seria representativo de uma tendência à concentração industrial. Especificamente, São Paulo apresentou acentuada vantagem nesse particular, também observada de forma mais discreta para Minas Gerais.

Pacheco (1999) emprega dados do IBGE referentes aos censos industriais de 1970 a 1985, e da Pesquisa Industrial Mensal - PIM - na versão produção física, dados sobre intenções de investimentos fornecidos pelo Ministério da Indústria, além dos dados do CAGED e da RAIS. O autor considerou medidas semelhantes às de Diniz e Crocco (1996) para as grandes regióes e estados brasileiros, calculando as participaçóes porcentuais segundo gêneros da indústria. $\mathrm{O}$ estudo mostra uma desconcentração, no período de 1970 a 1985, captada a partir do valor da transformação industrial para os estados e as grandes regiões. Uma análise com dados mais desagregados, segundo gêneros e abarcando o período 1986 a 1996 (com estatísticas de emprego), indicou uma discreta desconcentração. $\mathrm{O}$ trabalho conclui que as mudanças nos padróes locacionais não são uniformes, havendo padrões setoriais distintos.

O estudo de Saboia (2000) utiliza exclusivamente dados agregados da RAIS segundo as grandes regiões, os estados e as microrregiões, por gêneros de indústria para o período compreendido entre 1989 e 1997. O autor considera em sua análise taxas de variação para emprego, número de estabelecimentos e o tamanho médio destes. Em nível mais agregado evidencia-se um movimento de desconcentração presentes nas grandes regiốes e estados. Adicionalmente, é constatada uma migração do emprego industrial 
das capitais para o interior de boa parte dos estados. Com relação às microrregióes (classificadas em termos de quatro categorias por volume de emprego), constata-se um crescimento das aglomerações pequenas (com 5.000 a 10.000 empregados). A análise setorial está baseada nos cinco maiores gêneros empregadores em cada microrregião. Chega-se à conclusão de que as microrregiões mais especializadas apresentam melhor desempenho em termos do crescimento do emprego.

Suzigan et al. (2001) recorreu a dados agregados da RAIS que serviram de base para estudos de caso para um conjunto de microrregiốes do Estado de São Paulo. A medida empregada foi um índice de especialização obtido pela razão entre o emprego em dado setor e o total de emprego, ambos medidos para uma dada microrregião. O trabalho, em certo sentido, corrobora os resultados do trabalho, anteriormente mencionado, de Saboia. Com efeito, verifica-se um dinamismo das microrregiões no interior do estado. Outrossim, merece destaque a ampla heterogeneidade dessas mesmas aglomerações, requerendo, portanto, cuidados adicionais no exercício de formulação de políticas industriais.

Lage (2002) faz uso de dados do IBGE provenientes do Censo Industrial (para 1970, 1975 e 1985) e ainda de dados da Pesquisa Industrial Anual-PIA para o período 1996/ 97. O autor utiliza o índice de especialização de Krugman, o índice de Gini e ainda vetores de características industriais no nível estadual. Além da utilização de métodos estatísticos multivariados para identificar padrôes de especialização e concentração, o autor considera um modelo econométrico no qual a variável dependente é a participação de gêneros industriais por estado. Como variáveis explicativas aparecem as participaçóes da população e do produto com respeito ao agregado nacional e os vetores de características, sendo um relativo ao estado e outro ao gênero. Dentre os principais resultados destacam-se a importância de setores tecnologicamente sofisticados e da liberalização comercial na determinação da concentração. Ao contrário da maioria dos estudos anteriormente citados, que enfatizam aspectos descritivos, este último procura investigar econometricamente os determinantes da concentração.

Em conjunto, os estudos mostram que conclusões mais interessantes emergem à medida que aumenta o nível de desagregação das informações. Vale ressaltar que a quase totalidade dos estudos anteriores sobre aglomeração industrial possui um perfil descritivo amparado em medidas de caráter mais agregado, náo fundamentados em formalizaçôes teóricas. Alternativamente, Lage (2002) empreende um esforço de caracterização dos determinantes da aglomeração no nível setorial, explicitando a relevância das especificidades setoriais. Portanto, especificamente quanto às medidas de aglomeração, caracterizações mais precisas efetuadas com dados no nível de estabelecimentos podem representar um avanço importante na literatura brasileira. Esta é a principal motivação para a metodologia adotada no presente estudo. 


\section{MEDIDAS DE AGLOMERAÇÃO}

A investigação de padrões de localização industrial tem se beneficiado de uma crescente literatura que considera medidas sumárias de aglomeração industrial. Tais medidas incorporam, de diferentes modos, dimensões relativas à concentração industrial e espacial da atividade econômica. Apresentam-se, a seguir, alguns indicadores recentemente propostos na literatura. Nesse tocante, destaca-se o trabalho abrangente de Devereux, Griffith e Simpson-DGS (2004) que desenvolveu estudo aplicado em termos das diferentes medidas de aglomeração.

\subsection{A Medida de Aglomeração de Devereux et al.-DGS (2004)}

O ponto de partida das diferentes medidas de aglomeração associa-se a alguma medida de concentração. $\mathrm{O}$ índice de Herfindahl constitui a base das medidas a serem aqui discutidas. Com efeito, a referida medida tem sido freqüentemente utilizada na literatura de Economia Industrial em face das suas propriedades superiores relativamente a medidas mais simplificadas como as chamadas razões de concentração. ${ }^{3} \mathrm{O}$ índice de Herfindahl considerado no contexto da concentração industrial pode ser definido como:

$$
H=\sum_{i=1}^{n} s_{i}^{2}
$$

onde $s_{i}^{2}$ denota o quadrado da parcela de mercado da i-ésima firma em uma indústria composta por $\mathrm{n}$ firmas. ${ }^{4} \mathrm{O}$ esquema proposto propốe que seja atribuído um peso relativamente maior para firmas com parcelas de mercado mais elevadas. A medida situa-se necessariamente entre $1 / n$ e 1 . O limite superior corresponderia ao caso de monopólio em que uma única empresa detém todo o mercado, ao passo que o limite inferior estaria associado ao caso em que as diferentes firmas dividem igualmente o mercado. ${ }^{5} \mathrm{O}$ índice de Herfindahl é uma medida que reflete tanto o número de firmas quanto a variabilidade das parcelas de mercado, Com efeito, pode-se mostrar que: ${ }^{6}$

$$
H=\frac{1}{N}\left[1+C V\left(s_{i}\right)^{2}\right]
$$

3 Ver RESENDE \& BOFF (2002) para uma apresentação abrangente das medidas de concentração industrial.

4 Utiliza-se aqui o termo firma de forma livre. De fato, o presente estudo assim como outros considerados para outros países calculam aglomeraçóes a partir de dados referentes a estabelecimentos industriais.

5 Ver o apêndice 1 para detalhes.

6 Ver o apêndice 1. 
onde $\mathrm{CV}\left(\mathrm{s}_{\mathrm{i}}\right)^{2}$ representa o quadrado do coeficiente de variação das parcelas de mercado. Esse resultado se mostrará importante para as medidas de aglomeração que serão consideradas posteriormente. Pode-se conceber também uma medida de concentração espacial análoga àquela dada pela expressão (1). Especificamente considere:

$$
J=\sum_{j=1}^{K} s_{j}^{2}
$$

onde $s_{j}^{2}$ denota o quadrado da parcela j-ésima localidade relativamente ao total da variável de interesse (por exemplo: número de empregados em diferentes aplicações). Para um dado setor de indústria procura-se quantificar a concentração espacial quando existem $\mathrm{K}$ localidades possíveis.

Isto posto, uma medida simples para a aglomeração espacial pode ser definida como o excedente da concentração espacial relativamente à concentração industrial de um dado setor da indústria. A aglomeração seria definida como a concentração espacial condicional à concentração industrial dada por $\mathrm{J}-\mathrm{H}$. O inconveniente dessa medida, contudo, fica claro no caso que $\mathrm{N}>\mathrm{K}$. Considere, por exemplo, um caso em que as unidades de análise (por exemplo estabelecimentos) estejam igualmente distribuídas entre localidades e que possuam tamanhos idênticos. Por exemplo, caso tivéssemos $\mathrm{K}$ $=2, \operatorname{com}\left\{\mathrm{s}_{1}, \mathrm{~s}_{2}\right\}=\{0,5 ; 0,5\}$ e $\mathrm{N}=4, \operatorname{com}\left\{\mathrm{s}_{1}, \mathrm{~s}_{2}, \mathrm{~s}_{3}, \mathrm{~s}_{4}\right\}=\{0,25 ; 0,25 ; 0,25$; $0,25\}$, teríamos $\mathrm{J}=0,5^{2}+0,5^{2}=0,5>0,25^{2}+0,25^{2}+0,25^{2}+0,25^{2}=0,25=$ $\mathrm{H}$, e assim a medida $\mathrm{J}-\mathrm{H}=0,25$ indicaria aglomeração, embora o correto fosse a não existência da mesma. Para dar conta desse tipo de problema, Devereux et al. (1999) consideram uma medida que faz uso do resultado indicado na expressão (2). Especificamente sugere-se que:

$$
M=\sum_{i=1}^{N}\left[s_{i}-\frac{1}{N}\right]^{2}=\frac{C V\left(s_{i}\right)^{2}}{N}=H-\frac{1}{N}
$$

isto é, a expansão do quadrado do primeiro termo e a utilização da expressão (2) levam facilmente ao resultado indicado. De modo análogo, poder-se-ia definir uma medida semelhante para a concentração espacial:

$$
G=\sum_{j=1}^{K}\left[s_{j}-\frac{1}{K}\right]^{2}=\frac{C V\left(s_{j}\right)^{2}}{K}=J-\frac{1}{K}
$$

Conforme observado anteriormente, tem-se que $\mathrm{H}$ e J se igualam, respectivamente, a 1/N e $1 / \mathrm{K}$ no caso de distribuições uniformes da variável de estudo dentro da indústria e entre localidades. Vale dizer, tanto M quanto G seriam identicamente nulos independentemente de $\mathrm{N}$ e K. Tal propriedade é conveniente para dar conta do problema su- 
pramencionado quando se tem $N>K$. Em princípio, poder-se-ia conceber uma medida de aglomeração definida como a concentração espacial condicional à concentração industrial do setor de atividade $(\mathrm{G}-\mathrm{M})$. Todavia, um último ajuste na medida G é justificável e segue a seguinte medida de concentração espacial:

$$
F=\sum_{j=1}^{K}\left[s_{j}-\frac{1}{K^{*}}\right]^{2}=J-\frac{1}{K^{*}}
$$

onde $K^{*}=\min [N, K]$. A lógica subjacente a tal ajuste é simples. Caso se tenha $N<K$, o número máximo de localidades em que se tenham plantas seria $N$. Do ponto de vista do cálculo de $\mathrm{J}$, existiriam parcelas nulas em algumas localidades que não afetariam a concentração espacial conforme medida por $J$. O mesmo, contudo, não ocorreria com G, o que fornece uma justificativa plausível para se controlar pelo número máximo de regiôes em que uma indústria possa estar localizada. Assim, pode-se considerar a seguinte medida intuitiva de aglomeração proposta por aqueles autores:

$$
\alpha_{D G S}=F-M
$$

Tem-se que $-1<\alpha_{D G S}<1$ e que claramente $\alpha_{D G S}=0$ no caso de distribuiçốes uniformes de tamanho dos estabelecimentos dentro da indústria e entre localidades onde existem. As medidas aproximam-se dos extremos dos intervalos quando um grande número de firmas (todas com a mesma participação) encontra-se em uma mesma localidade $\left(\alpha_{D G S} \rightarrow 1\right)$ ou então quando há um grande número de firmas, considerando-se uma única localidade, sendo que uma delas possui participação de mercado beirando a totalidade $\left(\alpha_{D G S} \rightarrow-1\right)$. Outras medidas como aquelas propostas por Ellison e Glaeser (1997) e Maurel e Sédillot (1999) podem ser consideradas como medidas mais gerais nas quais procura-se controlar para diferenças de tamanho entre os diferentes setores de indústria relativamente à indústria como um todo.

\subsection{A Medida de Aglomeração de Maurel e Sédillot-MS (1999).}

Os autores propõem a seguinte medida de aglomeração:

$$
\gamma_{M S}=\frac{G_{M S} /(1-X)-H}{1-H}
$$

onde $G_{M S}=\left(\sum_{j=1}^{K} s_{j}^{2}-\sum_{j=1}^{K} x_{j}^{2}\right)$, onde $\mathrm{X}=\sum_{j=1}^{K} x_{j}^{2}, \operatorname{com} x_{j}$ indicando (na aplicação a seguir) a participação da j-ésima localidade no total de emprego da indústria de transformação como um todo. O termo $G_{M S}$ pretende controlar para as diferenças de 
tamanhos entre as localidades tomando como referência a participação de cada localidade no emprego total. Esta medida de aglomeração é semelhante à proposta por Ellison e Glaeser-EG (1997), conforme será visto na próxima subseção. A medida de aglomeração $\gamma_{M S}$ é justificada a partir de um modelo probabilístico de localização de plantas. Considere, segundo a notação adotada, uma indústria com $\mathrm{N}$ plantas dadas $\mathrm{K}$ possíveis localidades distintas. Pode-se escrever a participação do emprego da indústria localizado na área geográfica j como:

$$
s_{j}=\sum_{i=1}^{N} s_{i} u_{i j}
$$

onde $u_{i j}=1$ quando a planta i está presente na localidade $\mathrm{j}$ e 0 caso contrário. A formulação proposta por EG serve de base para a medida de MS. A idéia básica é conceber uma medida de aglomeração que aproxime a relação entre as decisões de localização de diferentes pares de plantas. ${ }^{7}$ Mais especificamente deseja-se ter $\rho\left(u_{i j}, u_{s j}\right)$ $=\gamma$ para $i \neq s$, tal que $-1 \leq \gamma \leq 1$ de modo que a medida de aglomeração seria identificada com o coeficiente de correlação entre as decisões locacionais dos diversos pares de plantas e aproximaria a importância de fatores relativos às externalidades. Para compreender-se melhor a medida $\gamma_{M S}$ deve-se ressaltar que $u_{i j}$ são variáveis aleatórias não independentes com distribuição de Bernouilli, de modo que $P\left(u_{i j}=1\right)=x_{j}$. Caso se considere a probabilidade de duas plantas i e $s$ se localizarem na mesma área $\mathrm{j}$ tem-se uma probabilidade independente de i e s, que é dada por:

$$
p(j, j)=E\left(u_{i j} u_{s j}\right)=\operatorname{Cov}\left(u_{i j}, u_{s j}\right)+E\left(u_{i j}\right) E\left(u_{s i}\right)=\gamma x_{j}\left(1-x_{j}\right)+x_{j}^{2}
$$

O termo envolvendo covariância segue diretamente da definição do coeficiente de correlação, ao passo que a última igualdade também utiliza resultados associados à distribuição de Bernouilli, que neste caso possui valor esperado igual à $x_{j}$ e variância $\left(1-x_{j}\right) x_{j}$. A probabilidade expressa em (11) indica o caso para uma dada localidade. Neste caso, se estivermos interessados na probabilidade de duas plantas localizarem-se em localidades idênticas quaisquer que sejam essas teríamos:

$$
p=\sum_{j=1}^{K} p(j, j)=\gamma\left(1-\sum_{j=1}^{K} x_{j}^{2}\right)+\sum_{j=1}^{K} x_{j}^{2}
$$

Define-se, portanto, uma relação linear ente $p$ e $\gamma$. Nesse contexto, MS propõem um estimador para $p$ definido em termos da proporção do número de pares de plantas situados em cada localidade relativamente ao total de plantas em todas as localidades, onde se utilizam como pesos a participação de cada planta no emprego da indústria $\left(s_{i}\right)$. A

7 OVERMAN et al. (2001) enfatizam a importância de se incorporar o fator aleatório na decisão de localização de plantas no contexto do modelo de ELLISON \& GLAESER (1997), que, com efeito, tem fundamentos semelhantes à formulação de MAUREL \& SEDILLOT (1999). 
utilização desse estimador ponderado pelos autores decorre de sua relação com o índice de Herfindahl, conforme será evidenciado a seguir. O estimador em questão é dado por: ${ }^{8}$

$$
\hat{p}=\frac{\sum_{j=1}^{K} s_{j}^{2}-H}{1-H}
$$

Valendo lembrar que que $\mathrm{H}=\sum_{i} s_{i}^{2}$ e utilizando-se (11) e (12) tem-se:

$$
\hat{\gamma}_{M S}=\frac{\hat{p}-\sum_{j=1}^{K} x_{j}^{2}}{1-\sum_{j=1}^{K} x_{j}^{2}}=\frac{\frac{\sum_{j=1}^{K} s_{j}^{2}-H}{1-H}-\sum_{j=1}^{K} x_{j}^{2}}{1-\sum_{j=1}^{K} x_{j}^{2}}=\frac{\frac{\sum_{j=1}^{K} s_{j}^{2}-\sum_{j=1}^{K} x_{j}^{2}-H(1-X)}{1-H}}{1-X}
$$

Assim, tem-se finalmente:

$$
\hat{\gamma}_{M S}=\frac{\frac{\sum_{j=1}^{K} s_{j}^{2}-\sum_{j=1}^{K} x_{j}^{2}}{1-\sum_{j=1}^{K} x_{j}^{2}}-H}{1-H}
$$

A comparação com a medida de aglomeração $\alpha$ discutida na subseção anterior indica pelo menos duas diferenças claras. Em primeiro lugar, a presença de um termo de escala $(1-\mathrm{H})$ e, em segundo lugar, a preocupação em controlar para diferenças de tamanhos entre o setor sob análise e a indústria como um todo. Para esse último aspecto, toma-se como referência os índices de concentração do setor focado e da indústria em termos agregados.

\subsection{A Medida de Aglomeração de Ellison e Glaeser-EG (1997)}

Os autores propõem a medida de aglomeração dada por:

8 A demonstração aparece no apêndice de MAUREL \& SÉDILLOT (1999). 


$$
\hat{\gamma}_{E G}=\frac{\sum_{j=1}^{K}\left(s_{j}-x_{j}\right)^{2} /(1-X)-H}{1-H}
$$

onde pode-se definir $G_{E G} \equiv \sum_{j=1}^{K}\left(s_{j}-x_{j}\right)^{2}$. Observa-se, portanto, que a diferença básica entre as duas últimas medidas de aglomeração se dá por conta dos termos $\mathrm{G}_{\mathrm{MS}} \mathrm{e}$ $G_{E G}$, este último contendo os termos cruzados entre $s$ e $x$.

No tocante à interpretação do índice, um caso interessante ocorre em uma indústria competitiva para a qual $\mathrm{H}$ tenderia para zero. Neste caso, G é simplesmente uma medida de concentração não afetada por aspectos da organização industrial. Quando $\hat{\gamma}_{E G}=$ 0 , tudo se passa como se a localização das firmas tivesse sido gerada aleatoriamente, como ocorreria caso a distribuição do emprego fosse uniforme entre as localidades (independentemente da distribuição espacial do emprego na indústria manufatureira como um todo). Tal situação serve como referência, por exemplo, para a interpretação de valores positivos para $\hat{\gamma}_{E G}$. Nesse contexto, este indicador estaria sinalizando um excesso de concentração. A conclusão é relativamente limitada, uma vez que não é possível identificar as causas da concentração que poderiam estar associadas a externalidades de aglomeração ou vantagens naturais da localidade. ${ }^{9}$

Desta forma, ficam indicadas três medidas alternativas de aglomeração que serão consideradas na aplicação empírica a ser discutida mais tarde. Convém salientar que valores positivos dessas medidas indicam setores de indústria em que os estabelecimentos tendem a situar-se espacialmente próximos (tendência à aglomeração), ao passo que valores negativos indicariam que o setor sob consideração exibe uma tendência à separação espacial.

\section{BASE DE DADOS}

Os principais índices de concentração industrial que aparecem sugeridos na literatura internacional - alguns em estudos para o Brasil - são calculados por meio do pessoal ocupado por área geográfica e setores de atividade. Em sintonia com esta tendência serão utilizadas, no presente estudo, as informaçóes que integram o acervo de registros

9 Essas interpretaçôes destacadas por ROSENTHAL \& STRANGE (2001). 
administrativos da Relação Anual de Informações Sociais - RAIS - do Ministério do Trabalho.

Preliminarmente, deve-se ressaltar os enormes obstáculos para que se efetue uma regionalização do produto industrial no Brasil. Em termos ideais, a variável de interesse para esta finalidade é o valor adicionado da indústria ou então - por meio de um conceito bem próximo - o valor da transformação industrial.

Com a interrupção dos censos econômicos, após 1985, o acompanhamento regular do setor industrial pelo IBGE tem sido feito por meio das pesquisas conjunturais da indústria, mais especificamente a PIM-PF (Pesquisa Industrial Mensal - Produção Física) e a PIM-DG (Versão Dados Gerais) e a Pesquisa Anual da Indústria (PIA), nas óticas das empresas e dos produtos.

Examinando-se iniciativas baseadas na PIM, ${ }^{10}$ conclui-se que seu emprego para fins de regionalização é uma tarefa arriscada, sendo duas as dificuldades mais relevantes. $\mathrm{Na}$ ausência de levantamentos censitários, capazes de gerar uma série temporal de valor adicionado da produção, os índices conjunturais precisam ser aplicados recursivamente sobre as bases antigas de 1980 (DG) e 1985 (PF). Além de longos horizontes de projeção, não há garantias - havendo evidências empíricas em contrário para a década de $1990^{11}$ - de que as proporçôes entre as variáveis do valor das vendas, valor da produção e o valor adicionado tenham sido mantidas estáveis, preocupação justificada pelo fato dos índices da PIM, nas versões PF e DG, acompanharem apenas a produção física e o volume de vendas. A eficácia da estimação dependeria de hipóteses fortes sobre as estatísticas de preços relativos e de produtividade dos fatores, ambas de notória variabilidade na economia brasileira dos anos $1990 .^{12}$

Uma outra fonte cogitada é a PIA que traz o VTI, estatística, em tese, adequada ao trabalho de regionalização, disponível em série anual desde 1986. Entretanto, a PIA prioriza (abordagem censitária) as empresas que ocupam 30 ou mais pessoas, realizando uma amostra probabilística para o caso das empresas menores. Tal desenho amostral é impróprio para o cálculo de medidas de concentração.

Adicionalmente, cabe registrar os esforços dos órgãos regionais de estatística para produzir estimativas do produto industrial dos municípios. Desde que sofram novas desagregações, talvez para gêneros ou para classes, estas fontes serão efetivas para o estudo

10 PACHECO (1999) e AZZONI (1997).

11 Vários estudos detectaram variaçôes significativas na produtividade da mão-de-obra, que normalmente afetam a razão valor da produção/valor adicionado como, por exemplo, em BONELLI \& FONSECA (1998).

12 Para mais detalhes é possível encontrar em ANDRADE \& SERRA (2000) uma resenha de estudos contendo nítidas evidências que apontam para mudanças recentes na produtividade da indústria brasileira. 
da aglomeração. Dentre as instituições empenhadas destacam-se a FEE (RS), a Fundação CIDE (RJ), a Fundação SEADE (SP) e a Fundação João Pinheiro (MG).

\section{Dados da RAIS}

Tendo em vista as dificuldades com fontes alternativas, cabe discutir as motivações para a adoção da RAIS visando à regionalização do produto industrial. Existem dois pontos essenciais. Inicialmente, verificar até que ponto os registros da RAIS são satisfatórios como "proxy" do emprego industrial, com a precisão espacial e setorial requeridas. Adicionalmente, é preciso saber se tal "proxy" é apropriada para efeito de rateio do valor adicionado industrial, visando aos recortes em microrregiôes com razoável precisão e confiabilidade.

Quanto à medição do nível de emprego, as críticas mais freqüentemente formuladas referem-se à "escolha" da população-alvo do levantamento. Estando restrita aos vínculos formais, a base deixa de fora uma parcela de ocupados que tem se revelado crescente ao longo do tempo. Neste sentido, e como fator atenuante, existem indícios de que na indústria de transformação há um baixo grau de informalidade do emprego quando comparado ao dos demais grandes setores da classificação do IBGE, assertiva que pode ser atestada por números da Pesquisa Nacional de Amostras por Domicílios e da Pesquisa Mensal de Emprego (Regiões Metropolitanas).

Na questão da divisão geográfica do emprego há dois aspectos a considerar. Ao contrário do que ocorria em bases mais remotas da RAIS - início dos anos 1990 - a cobertura tem mostrado mais homogênea pelas regiões do País, reduzindo uma fonte de viés para as medidas de concentração. Um problema difícil de contornar ocorre nas indústrias cujas empresas trabalham com várias plantas, já que algumas adotam sistemas centralizados para informar a RAIS, lotando todos os seus empregados em um único endereço (em geral na matriz). Uma evidência empírica é obtida comparando-se os números da RAIS com os da PIA. Nesta última pesquisa são consideradas empresas, diferentemente do que ocorre na RAIS, baseada em estabelecimentos. Uma empresa funcionando com vários estabelecimentos pode se fazer presente em várias localidades. Em 2000, por exemplo, a PIA considerou 124.778 empresas e a RAIS registrou 255.203 estabelecimentos, uma divergência que pode estar refletindo também as diferenças de natureza metodológica. O que de fato qualifica estes números como evidências empíricas da multiplicidade de plantas são os totais relativos ao do pessoal ocupado na PIA e na RAIS, que foram de 5.321 .106 e de 5.584 .010 indivíduos, respectivamente. Se não exatamente, ao menos em termos aproximados, e por caminhos diversos, ambas as pesquisas parecem abordar com precisão semelhante o mesmo universo. 
A discussão sobre a performance do volume de emprego na qualidade de indicador do nível de atividade econômica remete, outra vez, à questão das variaçốes na produtividade da mão-de-obra. Desde que confirmada a hipótese de que a produtividade da mãode-obra na indústria elevou-se drasticamente nos anos 1990 - havendo várias estimativas bem próximas de $7 \%$ ao ano -, é provável que este fator, associado à diversidade regional que caracteriza a economia brasileira, seja um elemento nada desprezível na introdução de viés das medidas convencionais de concentração geradas por meio das estatísticas de ocupação. Se as alterações na produtividade da mão-de-obra forem diferenciadas por setores da indústria, as medidas baseadas no emprego tenderam a mostrar movimentos de concentração nas áreas de menor incremento da produtividade.

Objetivamente, a questão que se coloca é a seguinte: seria possível formular medidas de concentração que, mesmo inspiradas em estatísticas de pessoal ocupado, tenham um comportamento neutro diante de mudanças na produtividade da mão-de-obra? Suporemos, na mesma linha de argumentação de Andrade e Serra (2000), que as unidades espaciais são amplas o suficiente para abrigar diversidade do ponto de vista da produtividade, e que os conjuntos de unidades industriais considerados incluem estabelecimentos com comportamentos distintos em relação à produtividade. Para regiốes menores, desde que com significância econômica, e para conjuntos de estabelecimentos mais homogêneos, é provável que as oscilações no nível de produtividade sejam igualmente menores.

Dentre os objetivos do estudo está o cálculo de medidas de concentração, adotando-se como unidade espacial as microrregióes econômicas e como unidades setoriais os estabelecimentos da indústria grupados segundo a classificação do CNAE4 adotada a partir de 1995, que em tais moldes adota implicitamente uma estratégia no sentido de reduzir os efeitos das distorçôes por mudanças na produtividade. Segue uma tabela que resume as principais características da base utilizada.

\section{TABELA 1-ESTATÍSTICAS DESCRITIVAS}

\begin{tabular}{lrr}
\hline Descrição & \multicolumn{1}{c}{1995} & \multicolumn{1}{c}{2001} \\
\hline Número de Indústrias (4 dígitos) & 274 & 274 \\
Número de Empregados & 5.502 .085 & 5.460 .132 \\
Número Total de Firmas & 214.535 & 253.721 \\
Número de Microrregiões & 552 & 555 \\
Número de Firmas sem localização & 5 & 115 \\
Número médio de Empregados & 25.65 & 21.52 \\
Desvio Padrão do № de Empregados & 158.99 & 116.18 \\
\hline
\end{tabular}




\section{RESULTADOS EMPÍRICOS}

Os resultados obtidos para as diferentes medidas de aglomeração a 4 dígitos podem ser encontrados na tabela apresentada no apêndice. Os valores obtidos evidenciam uma elevada heterogeneidade entre os diferentes setores da indústria de transformação. Com efeito, evidências globais são apresentadas na Tabela 2. As medidas de dispersão apontam para uma elevada variabilidade das medidas de aglomeração. Cumpre destacar que essa elevada heterogeneidade não é surpreendente em face do elevado nível de desagregação dos dados. Por outro lado, ficam evidentes sensíveis mudanças nos padrões de aglomeração ao longo do tempo. As diferenças são menos visíveis nos casos da média e da mediana, sendo, contudo, significativas no caso da assimetria e coeficiente de variação. Do ponto de vista conceitual, as duas últimas estatísticas podem ser interpretadas como indicativas de uma elevação da aglomeração industrial ao longo do tempo. Com a assimetria evidencia-se a presença de setores (4 dígitos) com viés de aglomeração (valores superiores a 0 ) ou de baixa aglomeração (valores inferiores a 0 ). Já o coeficiente de variação atua como um indicador geral da heterogeneidade das medidas de concentração.

TABELA 2 - MEDIDAS DE AGLOMERAÇÃO-ESTATÍSTICAS DESCRITIVAS

\begin{tabular}{|c|c|c|c|c|c|c|}
\hline \multirow{2}{*}{$\begin{array}{l}\text { Estatísticas } \\
\text { Descritivas }\end{array}$} & \multicolumn{2}{|c|}{$\alpha$} & \multicolumn{2}{|c|}{$\gamma_{E G}$} & \multicolumn{2}{|c|}{$\gamma_{M S}$} \\
\hline & 1995 & 2001 & 1995 & 2001 & 1995 & 2001 \\
\hline Média & 0.0978 & 0.0752 & 0.0563 & 0.0527 & 0.0665 & 0.0577 \\
\hline Mediana & 0.0775 & 0.0554 & 0.0311 & 0.0256 & 0.0434 & 0.0330 \\
\hline Máximo & 0.5651 & 0.7181 & 0.8251 & 0.9531 & 0.5799 & 0.8990 \\
\hline Mínimo & 0.0000 & 0.0000 & -0.8364 & -0.0680 & -0.0449 & -0.0288 \\
\hline Desvio padrão & 0.0866 & 0.0772 & 0.1100 & 0.0969 & 0.1002 & 0.0976 \\
\hline Coef. Variação & 0.8858 & 1.0262 & 1.9528 & 1.8370 & 1.5062 & 1.6915 \\
\hline Assimetria & 1.8860 & 3.4878 & 0.7591 & 4.7377 & 1.9420 & 3.8813 \\
\hline
\end{tabular}

Este panorama remete a uma busca pormenorizada de padrões de aglomeração que sejam específicos a certos setores. Nesse sentido, consideramos a seguir os 20 setores com maior grau de aglomeração. ${ }^{13}$ Os resultados correspondentes são apresentados na Tabela $3 .^{14}$

13 DEVEREUX et al (2004) empreenderam análise semelhante.

14 A tabela com as medidas de aglomeração para a totalidade dos setores a 4 dígitos aparece no apêndice 2. 


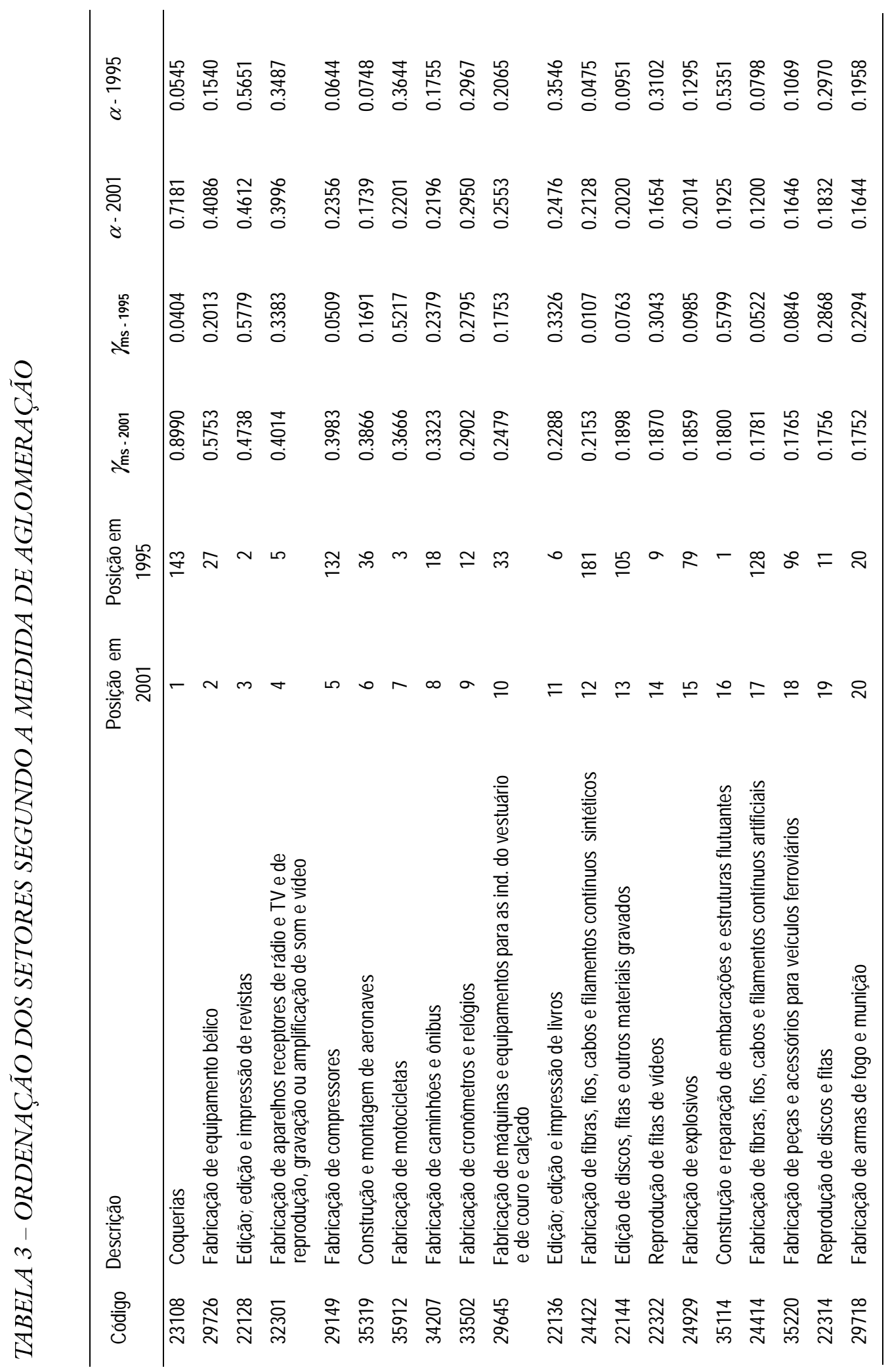

Est. econ., São Paulo, 35(3): 433-460, jul-set 2005 
A referida tabela apresenta os 20 setores com maior aglomeração segundo a medida $\gamma_{M S}$. Dentre os setores com maior aglomeração observa-se um setor cuja decisão locacional é parcialmente predeterminada por força de condicionantes naturais, especificamente o setor de coquerias. É este mesmo fato que justifica a desconsideração de setores da indústria extrativa mineral no presente estudo. Observa-se também a presença de setores com distintos conteúdos tecnológicos. Por fim, deve-se observar, na maioria dos setores mais aglomerados, uma grande diferença quanto à ordenação entre os anos de 1995 e 2001. De fato, dentre os 20 principais setores, em 2001, 9 não ocupavam lugares entre os 30 principais em 1995. Para ganhar perspectiva dos resultados, vale a pena comparar os atuais resultados com a evidência obtida por Maurel e Sedillot (1999) em estudo semelhante para a França. Embora possa ser observada semelhança quanto à magnitude das medidas de aglomeração, os setores responsáveis por tais resultados são outros. Ainda assim, pode-se observar pelo menos seis setores comuns entre os mais aglomerados. ${ }^{15}$ Merecem menção os setores de fabricação de relógios, gravação de som, edição de livros e revistas, fabricação de armas e indústria naval. Por outro lado, setores relacionados ao processamento de lã mostraram-se importantes na França. Vale ressaltar que Devereux et al. (2004) obtiveram resultados análogos para esses mesmos setores no caso do Reino Unido utilizando uma medida similar de aglomeração. O presente estudo não pretende investigar os determinantes da aglomeração industrial que no nível empírico exigiriam um esforço econométrico que ultrapassam os objetivos desse trabalho. Em tese, pode-se destacar a partir da literatura classes de fatores explicativos para diferentes regularidades associadas à aglomeração. Nesse tocante, parece haver consenso entre os diferentes autores quanto à existência de dois grandes grupos de fatores explicativos. Em primeiro lugar destacam-se vantagens naturais e de custos que essencialmente relacionam-se à disponibilidade local de fatores de produção e aspectos de mobilidade como, por exemplo, oferta adequada de energia, água e transportes. Em segundo lugar merecem menção as chamadas externalidades de aglomeração que congregam efeitos de externalidades de conhecimento (tipicamente associadas a gastos de $\mathrm{P} \& \mathrm{D}$ ) e vantagens associadas à estrutura de mercado em termos de um maior poder de barganha dos compradores cuja facilidade de obter descontos preferenciais está diretamente associada a maior prevalência de economias de escala por parte do fornecedor (ver, por exemplo, ROSENTHAL \& STRANGE, $2001 \mathrm{e}$ HENDERSON et al., 2001). É nesse ponto que o esforço econométrico faria sentido, elucidando dentre os fatores mencionados aqueles capazes de explicar a aglomeração. Para o caso brasileiro, deve-se observar que há pouca disponibilidade de informação para esse tipo de análise. Assim sendo, procederemos a uma análise baseada em estatísticas de correlação entre as medidas de aglomeração nos moldes de outros estudos para países desenvolvidos (ver, por exemplo, DEVEREUX et al., 2004). Neste sentido, a Tabela 4 apresentada a seguir fornece os coeficientes de correlação de Pearson e Spearman para a totalidade dos setores a 4 dígitos.

15 Os autores consideraram setores da indústria extrativa na análise, dentre os quais 5 situaram-se entre os mais aglomerados. 


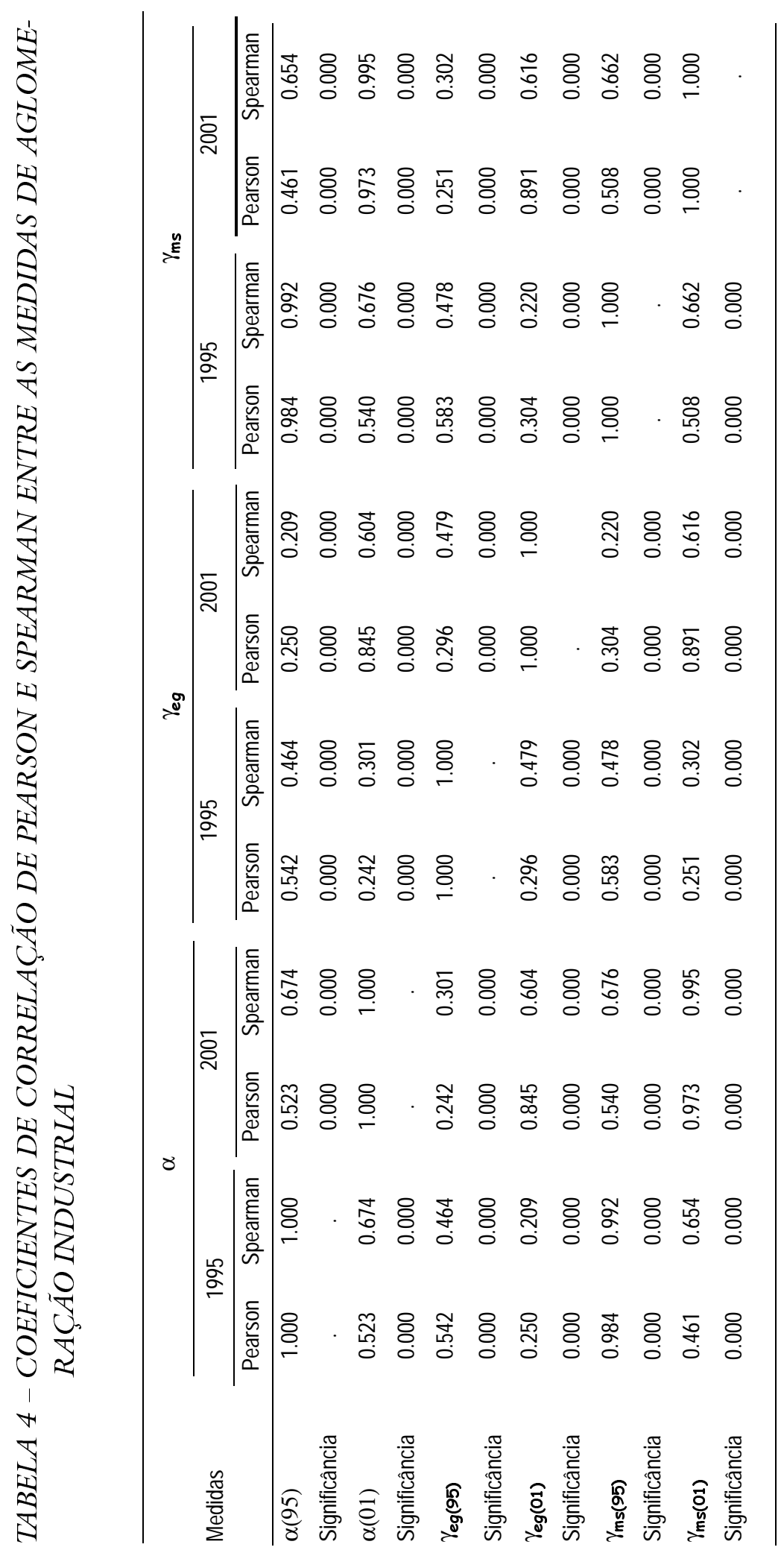

Est. econ., São Paulo, 35(3): 433-460, jul-set 2005 
A partir da tabela anterior iremos conduzir duas linhas de argumentação. Em primeiro lugar, estaremos interessados no grau de associação entre as diferentes medidas em um dado ano. Para tanto é utilizado o coeficiente de Pearson, que embora significativo em todos os casos, mostrou-se bastante variável com valores situando-se entre 0,25 e 0,98 . Os valores sistematicamente positivos do coeficiente atestam a consistência das medidas, já que, teoricamente, todas elas variam no mesmo sentido diante de uma mudança no grau de aglomeração. Os valores mais baixos dos coeficientes de correlação entre determinados pares de medidas fornecem evidências de que estas captam dimensões distintas do fenômeno. Deve-se ressaltar, contudo, o caráter exploratório da análise anterior, uma vez que coeficientes de correlação captam o grau de associação linear entre duas variáveis. ${ }^{16}$ Em segundo lugar, é relevante comparar a ordenação dos setores segundo cada medida entre os diferentes anos. Neste caso, utilizase o coeficiente de Spearman, que se situou entre 0,47 e 0,67, significativos, o que evidencia a ocorrência de mudanças importantes na ordenação dos setores entre 1995 e 2001 .

\section{COMENTÁRIOS FINAIS}

O presente artigo procurou quantificar a aglomeração na indústria de transformação brasileira para os anos de 1995 e 2001. Para tanto, consideramos medidas, recentemente desenvolvidas na literatura, que consideram um modelo probabilístico sobre a decisão de localização de plantas. Para o caso brasileiro, o principal obstáculo para a implementação dessas medidas estava associado à não disponibilidade de microdados, mais especificamente no nível de estabelecimento industrial. Neste sentido, o acesso às bases de microdados da RAIS ampliou os horizontes de pesquisa no âmbito da localização industrial.

Os resultados da pesquisa respondem a algumas perguntas importantes. Em particular, não existe um padrão de aglomeração comum aos diferentes setores de 4 dígitos da indústria de transformação. Quando se empreende uma comparação com estudos semelhantes para outros países constata-se que a ordem de grandeza das medidas para os setores líderes são muito próximas, contudo só se observam coincidências parciais em termos dos referidos setores. Ao longo do tempo notam-se importantes mudanças no que concerne à ordenação dos setores entre os anos de 1995 e 2001. Por exemplo, as distribuiçôes das medidas de aglomeração mostram um movimento simultâneo de elevação dos respectivos coeficientes de assimetria. Isto significa que entre 1995 e 2001 elevou-se a proporção de setores com baixo grau de aglomeração.

16 As expressões para $\gamma_{E G}$ e $\gamma_{M S}$ podem ser contrastadas em termos de um termo cruzado que confere uma não-linearidade à relação entre essas medidas de aglomeração. 
São inúmeros os desdobramentos possíveis a partir dessa linha de pesquisa. Por exemplo, padrốes das distribuições das medidas de aglomeração poderiam ser mais explorados estatisticamente. Há também a possibilidade de estudos para medir a coaglomeração, que identifica padrões de aglomeração comuns a subsetores. Por fim, seria oportuno o desenvolvimento de modelos econométricos que pudessem explicitar os fatores responsáveis pela aglomeração industrial. Estes desdobramentos fogem, contudo, ao escopo do presente trabalho.

\section{REFERENCIAS}

ANDRADE, T.A. Métodos estatísticos e econométricos aplicados à análise regional. In: HADDAD, P. R.; FERREIRA, C. M. C.; BOISIER, S.; ANDRADE, T.A. (eds.), Economia regional: teorias e métodos de análise. Fortaleza: Banco do Nordeste do Brasil, 1989.

ANDRADE, T. A.; SERRA, R. V. Distribuição espacial da indústria: possibilidades atuais para sua investigação. Estudos Econômicos, v. 30, n. 2, p. 207-231, abr./ jun. 2000.

AUDRETSCH, D. B. Agglomeration and the location of innovative activity. Oxford Review of Economic Policy, 14, 1998.

AZEVEDO, P. F.; TONETO JÚNIOR, R. Fatores determinantes da relocalização industrial na década de 90. 1999.

AZZONI, C. R. Concentração regional e dispersão das rendas per capita estaduais: análise a partir das séries históricas estaduais de PIB, 1939-95. Estudos Econômicos, 27, n. 3, p. 341-393, set./dez. 1997.

CANO, W. Raizes da concentração industrial em São Paulo. São Paulo: DIFEL, 1977. . Desequilibrios regionais e concentração industrial no Brasil. São Paulo: Global, 1985.

CASTRO, A. B. 7 ensaios sobre a economia brasileira. Rio de Janeiro: Forense, 1971.

DEVEREUX, M. P.; GRIFFITH, R.; SIMPSON, H. The geographic distribution of production activity in the UK. Regional Science and Urban Economics, 34, p. 533-564, 2004.

DINIZ, C. C. A questão regional e as políticas governamentais no Brasil. Texto para Discussão $n^{0}$ 159, CEDEPLAR, Universidade Federal de Minas Gerais, 2001.

DINIZ, C. C.; CROCCO, M. A. Reestruturação econômica e impacto regional: o novo mapa da indústria brasileira. Nova Economia, 6, p. 77-103, 1996.

DUMAIS, G.; ELLISON, G.; GLAESER, G. Geographic concentration as a dynamic process. Cambridge-MA, NBER Working Paper n. 6270, 1997.

DURO-MORENO, J. A. Cross-country inequalities in aggregate welfare: some evidence. Applied Economics Letters, 8, p. 403-406, 2001. 
ELLISON, G.; GLAESER, G. Geographic concentration in U.S. manufacturing industries: a dartboard approach. Journal of Political Economy, 105, p. 889927, 1997.

FELIPE, J.; RESENDE, M. A multivariate approach to the measurement of development: Asia and Latin America. Joumal of Developing Areas, 30, p. 183-210, 1996.

FERREIRA, P. C.; ELLERY, R. G. Convergência da renda per capita dos estados brasileiros. Revista de Econometria, 16, p. 83-104, 1996.

FURTADO, C. Formação econômica do Brasil. São Paulo: Editora Nacional, 1959.

GÖRG, H.; STROBL, E.; RUANE, F. Determinants of firm start-up size: an application of quantile regression for Ireland. Small Business Economics, 14, p. 211-222, 2000.

GÖRG, H.; STROBL, E. Multinational companies and entrant start-up size: evidence from quantile regressions. Review of Industrial Organization, 17, p. 1531, 2002.

HADDAD, P. R. Medidas de localização e de especialização. In: HADDAD, P. R. (org.), Economia regional: teorias e métodos de análise. Fortaleza: BNBETENE, 1989.

HENDERSON, J.; SHALIZI, Z.; VENABLES, A. Geography and development. Journal of Economic Geography, 1, p. 81-105, 2001.

HOOVER, E. Location theory and the shoe and leather industries. Cambridge-MA: Harvard University Press, 1936.

ISARD, W. Location and space-economy. Cambridge-MA: MIT Press, 1956. . Methods of regional analysis. Cambridge-MA: MIT Press, 1960.

JUDGE, G.; HILL, R.; GRIFFITHS, W.; LUTKEPOHL, H.; LEE, T. Introduction to the theory and practice of econometrics. Chichester: John Wiley \& Sons, 1988.

KRUGMAN, P. Geography and trade. Cambridge-MA: MIT Press, 1991.

KRUGMAN, P.; VENABLES, A. Globalization and inequality of nations. QuarterLy Journal of Economics, 110, p. 857-80, 1995.

LAGE, F. L. A localização da indústria de transformação brasileira nas últimas três décadas. 2002. Dissertação (Mestrado), EPGE/FGV, Rio de Janeiro.

MATA, J.; MACHADO, J. A. F. Firm start-up size: a conditional quantile approach. European Economic Review, 40, p. 1305-1323, 1996.

MAUREL, F.; SÉDILLOT, B. A measure of the geographic concentration in French manufacturing industries. Regional Science and Urban Economics, 29, p. 575-604, 1999.

NAJBERG, S.; PUGA, F. P.; OLIVEIRA, P. A. S. Sobrevivência das firmas no Brasil: Dez. 1995/Dez. 1997. Revista do BNDES, 7, p. 35-48, 2000. 
OVERMAN, H.; REDDING, S.; VENABLES, A. The economic geography of trade, production and income: a survey of empirics. Centre for Economic Policy Research Paper 2978, 2001.

PACHECO, C. A. Novos padrões de localização industrial? Tendências recentes dos indicadores da produção e do investimento industrial. Brasília, Textos para Discussão $n^{0}$ 633, Brasília: IPEA, 1999.

RESENDE, M.; BOFF, H. Concentração industrial. In: KUPFER, D.; HASENCLEVER, Lia (eds.), Economia industrial: teorias e prática no Brasil. Rio de Janeiro: Editora Campus, 2002, p. 73-90.

ROSENTHAL, S. S.; STRANGE, W. C. The determinants of agglomeration. Journal of Urban Economics, 50, p. 191-229, 2001.

SABOIA, J. L. Desconcentração industrial no Brasil nos anos 90: um enfoque regional. Pesquisa e Planejamento Econômico, 30, p. 69-116, 2000.

SCHMIDT, H. Global competition and local cooperation: success and failure in the Sinos Valley, Brazil. World Development, 27, p. 1627-1650, 1999.

SUZIGAN, W. Aglomerações industriais como focos de políticas. Revista de Economia Politica, 21, p. 27-39, 2001.

SUZIGAN, W.; FURTADO, J.; GARCIA, R.; SAMPAIO, S. E. K. Aglomerações industriais no Estado de São Paulo. Economia Aplicada, v. 5, n. 4, p. 695-717, out./dez. 2001.

\section{APÊNDICE 1}

\section{Índice de Concentração de Herfindabl: Alguns Resultados}

\section{a) Limite inferior do indice}

O valor mínimo do índice pode ser obtido a partir do problema de minimização indicado no lagrangeano a seguir:

$$
L=\sum_{i=1}^{n} s_{i}^{2}+\lambda\left[1-\sum_{i=1}^{n} s_{i}\right]
$$

onde $\lambda$ representa o multiplicador de Lagrange. Pelas condições de primeira ordem tem-se:

$$
\begin{aligned}
& \frac{\partial L}{\partial s_{i}}=2 s_{i}-\lambda=0 \\
& \frac{\partial L}{\partial \lambda}=1-\sum_{i=1}^{n} s_{i}=0
\end{aligned}
$$


Segue de (ii) que $s_{i}=\lambda / 2$. A substituição desse valor em (ii) indica que no mínimo $s_{i}=$ $1 / n$, o qual, substituído na expressão para o índice de Herfindahl, prontamente implica um limite inferior igual a $1 / n$.

\section{b) Índice de Herfindable desigualdade no tamanho das firmas}

$\mathrm{O}$ índice de Herfindahl exibe dependência em termos do número de firmas na indústria. Um segundo aspecto que merece menção refere-se ao componente de desigualdade do tamanho das firmas. Pode-se facilmente reescrever a variância amostral da variável de interesse de uma forma mais conveniente. Para tanto, basta operarmos o quadrado na expressão da variância e lembrarmos que a média amostral $\bar{X}$ é tal que $\mathrm{n} \bar{X}=\sum_{i} X_{i}$.

$$
s^{2} \equiv \frac{1}{N} \sum_{i=1}^{N}\left(X_{i}-\bar{X}\right)^{2}=\frac{1}{N} \sum_{i=1}^{N} X_{i}^{2}-\bar{X}^{2}
$$

Lembrando que o coeficiente de variação pode ser definido como $\mathrm{CV}=\mathrm{s} / \bar{X}$, tem-se que:

$$
C V^{2}=\frac{1}{N \bar{X}^{2}} \sum_{i=1}^{n} X_{i}^{2}-1
$$

Finalmente chega-se à seguinte expressão:

$$
\frac{1}{N}\left(C V^{2}+1\right)=\frac{1}{N^{2} \bar{X}^{2}} \sum_{i=1}^{N} X_{i}^{2}=\sum_{i=1}^{N}\left[\frac{X_{i}}{\sum_{i=1}^{N} X_{i}}\right]^{2}=\sum_{i=1}^{N} s_{i}^{2} \equiv H
$$

Portanto, observa-se a dependência do índice $\mathrm{H}$ relativamente ao quadrado do coeficiente de variação e ao número de firmas. 


\section{APÊNDICE 2}

\section{MEDIDAS DE CONCENTRAÇÃO PARA A INDÚSTRIA DE TRANSFOR- MAÇÃO, ADOTANDO COMO UNIDADE DE ÁREA AS MICRORREGIÕES DO IBGE, SEGUNDO A CLASSIFICAÇÃO CNAE COM 4 DÍGITOS. BRASIL - 1995/ 2001}

\begin{tabular}{|c|c|c|c|c|c|c|c|c|c|c|c|}
\hline \multirow{2}{*}{ Código } & \multirow{2}{*}{ Descrição do setor } & \multicolumn{5}{|c|}{1995} & \multicolumn{5}{|c|}{2001} \\
\hline & & $M$ & $F$ & $\alpha$ & $\gamma_{\mathrm{eg}}$ & $\gamma_{\mathrm{ms}}$ & $M$ & $F$ & $\alpha$ & $\gamma_{\mathrm{eg}}$ & $\gamma \mathrm{ms}$ \\
\hline 15113 & Abate de reses, preparação de produtos de carne & 0,0086 & 0,0235 & 0,0149 & 0,0484 & $-0,0286$ & 0,0080 & 0,0133 & 0,0054 & 0,0270 & $-0,0221$ \\
\hline 15121 & Abate de aves e outros pequenos animais e preparação de produtos de carne & 0,0191 & 0,0478 & 0,0287 & 0,0394 & $-0,0137$ & 0,0168 & 0,0287 & 0,0119 & 0,0294 & $-0,0158$ \\
\hline 15130 & Preparação de carne, banha e produtos de salsicharia não-associada ao abate & 0,0198 & 0,0310 & 0,0112 & 0,0234 & $-0,0329$ & 0,0133 & 0,0333 & 0,0200 & 0,0035 & $-0,0076$ \\
\hline 15148 & Prepar. e preservação do pescado e Fabric. de conservas de peixes, crustácios e moluscos & 0,0304 & 0,0743 & 0,0439 & $-0,0081$ & 0,0026 & 0,0266 & 0,1535 & 0,1270 & 0,1394 & 0,1061 \\
\hline 15210 & Processamento, preservação e produção de conservas de frutas & 0,0380 & 0,0585 & 0,0205 & 0,0498 & $-0,0225$ & 0,0321 & 0,0796 & 0,0475 & 0,0692 & 0,0218 \\
\hline 15229 & Processamento, preservação e produção de conservas de legumes e outros vegetais & 0,0503 & 0,1150 & 0,0647 & 0,1042 & 0,0267 & 0,0511 & 0,0596 & 0,0085 & 0,0128 & $-0,0195$ \\
\hline 15237 & Produção de sucos de frutas e de legumes & 0,0402 & 0,0522 & 0,0120 & 0,0351 & $-0,0317$ & 0,0213 & 0,0586 & 0,0373 & 0,0521 & 0,0106 \\
\hline 15318 & Produção de óleos vegetais em bruto & 0,0095 & 0,0236 & 0,0141 & 0,0211 & $-0,0300$ & 0,0238 & 0,0448 & 0,0211 & 0,0037 & $-0,0065$ \\
\hline 15326 & Refino de óleos vegetais & 0,0606 & 0,1624 & 0,1018 & 0,0131 & 0,0699 & 0,0375 & 0,0544 & 0,0168 & $-0,0018$ & $-0,0106$ \\
\hline 15334 & Prepar. de margarina e outras gorduras vegetais e de óleos de origem animal não-comestiveis & 0,1016 & 0,1402 & 0,0386 & 0,0194 & 0,0013 & 0,0969 & 0,0998 & 0,0029 & 0,0012 & $-0,0253$ \\
\hline 15415 & Preparação do leite & 0,0158 & 0,0229 & 0,0072 & 0,0462 & $-0,0365$ & 0,0091 & 0,0135 & 0,0044 & 0,0087 & $-0,0235$ \\
\hline 15423 & Fabricação de produtos do laticínio & 0,0042 & 0,0199 & 0,0157 & 0,0280 & $-0,0269$ & 0,0039 & 0,0168 & 0,0130 & 0,0049 & $-0,0139$ \\
\hline 15431 & Fabricação de sorvetes & 0,0150 & 0,0673 & 0,0523 & 0,0736 & 0,0121 & 0,0093 & 0,0266 & 0,0174 & $-0,0017$ & $-0,0094$ \\
\hline 15512 & Beneficiamento de arroz e fabricação de produtos do arroz & 0,0049 & 0,0285 & 0,0236 & 0,0608 & $-0,0188$ & 0,0036 & 0,0445 & 0,0409 & 0,0649 & 0,0145 \\
\hline 15520 & Moagem de trigo e fabricação de derivados & 0,0096 & 0,0267 & 0,0170 & 0,0230 & $-0,0268$ & 0,0114 & 0,0354 & 0,0240 & 0,0029 & $-0,0037$ \\
\hline 15539 & Fabricação de farinha de mandioca e derivados & 0,0216 & 0,0429 & 0,0213 & 0,0649 & $-0,0220$ & 0,0197 & 0,0838 & 0,0641 & 0,0930 & 0,0387 \\
\hline 15547 & Fabricação de fubá e farinha de milho & 0,0260 & 0,0313 & 0,0053 & 0,0448 & $-0,0392$ & 0,0221 & 0,0311 & 0,0090 & 0,0206 & $-0,0192$ \\
\hline 15555 & Fabric. de amidos e féculas de vegetais e fabric. de óleos de milho & 0,0573 & 0,1510 & 0,0937 & 0,1165 & 0,0602 & 0,0528 & 0,0722 & 0,0194 & 0,0462 & $-0,0074$ \\
\hline 15563 & Fabricação de rações balanceadas para animais & 0,0081 & 0,0141 & 0,0059 & 0,0322 & $-0,0382$ & 0,0053 & 0,0164 & 0,0111 & 0,0119 & $-0,0165$ \\
\hline 15598 & Beneficiamento, moagem e preparaçao de outros alimentos de origem ... & 0,0192 & 0,0576 & 0,0384 & 0,0719 & $-0,0029$ & 0,0160 & 0,0510 & 0,0350 & 0,0477 & 0,0088 \\
\hline 15610 & Usinas de açúcar & 0,0067 & 0,0569 & 0,0503 & 0,0756 & 0,0082 & 0,0110 & 0,0621 & 0,0511 & 0,0760 & 0,0245 \\
\hline 15628 & Refino e moagem de açúcar & 0,1320 & 0,1566 & 0,0246 & $-0,0126$ & $-0,0145$ & 0,1740 & 0,1803 & 0,0063 & 0,0123 & $-0,0207$ \\
\hline 15717 & Torrefação e moagem de café & 0,0061 & 0,0142 & 0,0081 & 0,0395 & $-0,0353$ & 0,0074 & 0,0154 & 0,0080 & 0,0081 & $-0,0195$ \\
\hline 15725 & Fabricação de café solúvel & 0,1094 & 0,1113 & 0,0019 & 0,0187 & $-0,0425$ & 0,1182 & 0,1920 & 0,0738 & 0,1047 & 0,0593 \\
\hline 15814 & Fabricação de produtos de padaria, confeitaria e pastelaria & 0,0006 & 0,0257 & 0,0250 & 0,0095 & $-0,0169$ & 0,0005 & 0,0196 & 0,0191 & 0,0051 & $-0,0073$ \\
\hline 15822 & Fabricação de biscoitos e bolachas & 0,0267 & 0,0563 & 0,0297 & 0,0291 & $-0,0129$ & 0,0184 & 0,0468 & 0,0284 & $-0,0004$ & 0,0019 \\
\hline 15830 & Produçao de derivados do cacau e elaboração de chocolates, balas, gomas de mascar & 0,0306 & 0,0850 & 0,0544 & 0,0185 & 0,0139 & 0,0328 & 0,1146 & 0,0818 & 0,0226 & 0,0584 \\
\hline 15849 & Fabricação de massas alimentícias & 0,0063 & 0,0272 & 0,0209 & 0,0111 & $-0,0218$ & 0,0101 & 0,0355 & 0,0254 & 0,0093 & $-0,0011$ \\
\hline 15857 & Preparação de especiarias, molhos, temperos e condimentos & 0,1629 & 0,1970 & 0,0341 & 0,0149 & $-0,0021$ & 0,0939 & 0,1382 & 0,0443 & 0,0466 & 0,0216 \\
\hline 15865 & Prepar. de produtos dietéticos, alimentos para crianças e outros alimentos conservados & 0,0273 & 0,0648 & 0,0374 & 0,0010 & $-0,0045$ & 0,0267 & 0,0547 & 0,0280 & 0,0067 & 0,0011 \\
\hline 15890 & Fabricação de outros produtos alimentícios & 0,0065 & 0,0296 & 0,0231 & 0,0255 & $-0,0193$ & 0,0041 & 0,0270 & 0,0229 & 0,0027 & $-0,0036$ \\
\hline 15911 & Fabric., retificação, homogeneizaçao e mistura de aguardentes e outras bebidas destiladas & 0,0091 & 0,0270 & 0,0179 & 0,0294 & $-0,0256$ & 0,0078 & 0,0232 & 0,0153 & 0,0194 & $-0,0122$ \\
\hline 15920 & Fabricação de Vinho & 0,0188 & 0,1853 & 0,1665 & 0,1987 & 0,1330 & 0,0120 & 0,2042 & 0,1921 & 0,1914 & 0,1719 \\
\hline 15938 & Fabricação de malte, cervejas e chopes & 0,0218 & 0,0357 & 0,0139 & 0,0267 & $-0,0299$ & 0,0213 & 0,0386 & 0,0173 & 0,0001 & $-0,0105$ \\
\hline 15946 & Engarrafamento e gaseificação de águas minerais & 0,0122 & 0,0287 & 0,0165 & 0,0199 & $-0,0273$ & 0,0115 & 0,0354 & 0,0239 & 0,0297 & $-0,0038$ \\
\hline 15954 & Fabricação de refrigerantes e refrescos & 0,0055 & 0,0197 & 0,0142 & 0,0173 & $-0,0299$ & 0,0064 & 0,0202 & 0,0139 & 0,0110 & $-0,0142$ \\
\hline 16004 & Fabricação de produtos do fumo & 0,0303 & 0,0851 & 0,0548 & 0,0947 & 0,0145 & 0,0260 & 0,1395 & 0,1135 & 0,1056 & 0,0917 \\
\hline 17116 & Beneficiamento de algodão & 0,0484 & 0,0811 & 0,0327 & $-0,0151$ & $-0,0089$ & 0,0165 & 0,0261 & 0,0096 & 0,0175 & $-0,0187$ \\
\hline 17191 & Beneficiamento de outras fibras têxteis naturais & 0,0367 & 0,1202 & 0,0834 & 0,0145 & 0,0460 & 0,0179 & 0,0500 & 0,0322 & 0,0129 & 0,0051 \\
\hline 17213 & Fiação de algodão & 0,0120 & 0,0635 & 0,0515 & 0,0416 & 0,0098 & 0,0152 & 0,0451 & 0,0299 & 0,0354 & 0,0027 \\
\hline 17221 & Fiação de outras fibras têxteis naturais & 0,0533 & 0,0834 & 0,0300 & 0,0323 & $-0,0114$ & 0,0461 & 0,0819 & 0,0358 & 0,0544 & 0,0104 \\
\hline 17230 & Fiação de fibras artificiais ou sintéticas & 0,0339 & 0,0963 & 0,0623 & 0,0260 & 0,0230 & 0,0310 & 0,0713 & 0,0403 & 0,0200 & 0,0143 \\
\hline 17248 & Fabricação de linhas e fios para coser e bordar & 0,0842 & 0,2942 & 0,2101 & 0,2086 & 0,1973 & 0,1034 & 0,1425 & 0,0392 & $-0,0184$ & 0,0166 \\
\hline 17310 & Tecelagem de algodão & 0,0159 & 0,1373 & 0,1214 & 0,1333 & 0,0844 & 0,0186 & 0,0505 & 0,0319 & 0,0295 & 0,0048 \\
\hline 17329 & Tecelagem de fios de fibras têxteis naturais & 0,0488 & 0,1323 & 0,0835 & 0,0622 & 0,0472 & 0,0926 & 0,0988 & 0,0062 & 0,0113 & $-0,0217$ \\
\hline 17337 & Tecelagem de fios e filamentos contínuos artificiais ou sintéticos & 0,0118 & 0,2548 & 0,2430 & 0,1634 & 0,2127 & 0,0212 & 0,1558 & 0,1346 & 0,1089 & 0,1131 \\
\hline 17418 & Fabricação de artigos de tecido de uso doméstico incluindo tecelagem & 0,0367 & 0,1203 & 0,0836 & 0,0549 & 0,0460 & 0,0535 & 0,1089 & 0,0554 & 0,0352 & 0,0316 \\
\hline 17493 & Fabricação de outros artefatos têxteis incluindo tecelagem & 0,0238 & 0,1048 & 0,0810 & 0,0456 & 0,0425 & 0,0210 & 0,0715 & 0,0505 & 0,0322 & 0,0250 \\
\hline 17507 & Serv. de acabamento em fios, tecidos e artigos têxteis produzidos por terceiros & 0,0114 & 0,1251 & 0,1137 & 0,0404 & 0,0756 & 0,0058 & 0,0495 & 0,0437 & 0,0236 & 0,0168 \\
\hline 17612 & Fabricação de artefatos têxteis a partir de tecidos & 0,0139 & 0,0647 & 0,0508 & 0,0194 & 0,0095 & 0,0154 & 0,0593 & 0,0440 & 0,0274 & 0,0183 \\
\hline 17620 & Fabricação de artefatos de tapeçaria & 0,0569 & 0,2914 & 0,2345 & 0,0952 & 0,2159 & 0,0351 & 0,0541 & 0,0190 & $-0,0017$ & $-0,0084$ \\
\hline 17639 & Fabricação de artefatos de cordoaria & 0,0361 & 0,0965 & 0,0604 & $-0,0043$ & 0,0212 & 0,0513 & 0,1573 & 0,1060 & 0,0344 & 0,0871 \\
\hline 17647 & Fabricação de tecidos especiais - inclusive artefatos & 0,0433 & 0,1341 & 0,0908 & 0,0006 & 0,0556 & 0,0274 & 0,1015 & 0,0741 & 0,0093 & 0,0502 \\
\hline 17698 & Fabricação de outros artigos têxteis - exclusive vestuário & 0,0127 & 0,0728 & 0,0601 & 0,0078 & 0,0196 & 0,0206 & 0,0604 & 0,0398 & 0,0142 & 0,0138 \\
\hline 17710 & Fabricação de tecidos de malha & 0,0076 & 0,0479 & 0,0403 & 0,0288 & $-0,0014$ & 0,0091 & 0,0714 & 0,0624 & 0,0284 & 0,0368 \\
\hline
\end{tabular}

(continua) 
MEDIDAS DE CONCENTRAÇÃO PARA A INDÚSTRIA DE TRANSFORMAÇÃO, ADOTANDO COMO UNIDADE DE ÁREA AS MICRORREGIÓOES DO IBGE, SEGUNDO A CLASSIFICAÇÃO CNAE COM 4 DÍGITOS. BRASIL - 1995/ 2001 - (contimuação)

\begin{tabular}{|c|c|c|c|c|c|c|c|c|c|c|c|}
\hline \multirow{2}{*}{ Código } & \multirow{2}{*}{ Descrição do setor } & \multicolumn{5}{|c|}{1995} & \multicolumn{5}{|c|}{2001} \\
\hline & & $\bar{M}$ & $F$ & $\alpha$ & $\gamma e g$ & $\gamma \mathrm{ms}$ & $M$ & $F$ & $\alpha$ & $\gamma \mathrm{rg}$ & $\gamma \mathrm{ms}$ \\
\hline 17728 & Fabricação de meias & 0,0742 & 0,2274 & 0,1532 & 0,0456 & 0,1290 & 0,1187 & 0,1647 & 0,0460 & 0,0389 & 0,0254 \\
\hline 17795 & Fabric. de outros artigos do vestuário produzidos em malharias (tricotagens) & 0,0060 & 0,0438 & 0,0378 & 0,0418 & $-0,0039$ & 0,0138 & 0,1387 & 0,1250 & 0,1267 & 0,1030 \\
\hline 18112 & Confecção de peças interiores do vestuário & 0,0121 & 0,0683 & 0,0561 & 0,0195 & 0,0161 & 0,0055 & 0,0608 & 0,0553 & 0,0291 & 0,0300 \\
\hline 18120 & Confecção de outras peças do vestuário & 0,0006 & 0,0601 & 0,0596 & 0,0088 & 0,0193 & 0,0005 & 0,0412 & 0,0407 & 0,0102 & 0,0150 \\
\hline 18139 & Confecção de roupas profissionais & 0,0024 & 0,0559 & 0,0534 & 0,0102 & 0,0123 & 0,0032 & 0,0383 & 0,0351 & 0,0058 & 0,0087 \\
\hline 18210 & Fabricação de acessórios do vestuário & 0,0078 & 0,1182 & 0,1104 & 0,0243 & 0,0727 & 0,0034 & 0,0279 & 0,0245 & 0,0089 & $-0,0022$ \\
\hline 18228 & Fabricação de acessórios para segurança industrial e pessoal & 0,0179 & 0,1392 & 0,1214 & 0,0267 & 0,0848 & 0,0120 & 0,0914 & 0,0793 & 0,0196 & 0,0541 \\
\hline 19100 & Curtimento e outras preparações de couro & 0,0051 & 0,0270 & 0,0220 & 0,0474 & $-0,0211$ & 0,0066 & 0,0366 & 0,0300 & 0,0421 & 0,0029 \\
\hline 19216 & Fabric. de malas, bolsas, valises e outros artefatos para viagem, de qualquer material & 0,0070 & 0,1028 & 0,0958 & 0,0175 & 0,0567 & 0,0104 & 0,0735 & 0,0631 & 0,0183 & 0,0377 \\
\hline 19291 & Fabricação de outros artefatos de couro & 0,0225 & 0,0692 & 0,0466 & 0,0150 & 0,0061 & 0,0033 & 0,0520 & 0,0487 & 0,0362 & 0,0227 \\
\hline 19313 & Fabricação de calçados de couro & 0,0042 & 0,1589 & 0,1547 & 0,1688 & 0,1192 & 0,0034 & 0,1198 & 0,1164 & 0,1169 & 0,0931 \\
\hline 19321 & Fabricação de tênis de qualquer material & 0,0186 & 0,4501 & 0,4315 & 0,4793 & 0,4155 & 0,0207 & 0,1102 & 0,0894 & 0,1034 & 0,0655 \\
\hline 19330 & Fabricaçâo de calçados de plástico & 0,1612 & 0,1950 & 0,0338 & 0,0369 & $-0,0024$ & 0,2243 & 0,2800 & 0,0557 & 0,0972 & 0,0457 \\
\hline 19399 & Fabricação de calçados de outros materiais & 0,0146 & 0,0925 & 0,0778 & 0,0949 & 0,0387 & 0,0146 & 0,0873 & 0,0727 & 0,0826 & 0,0482 \\
\hline 20109 & Desdobramento de madeira & 0,0008 & 0,0119 & 0,0112 & 0,0475 & $-0,0314$ & 0,0005 & 0,0180 & 0,0174 & 0,0413 & $-0,0091$ \\
\hline 20214 & Fabric. de madeira laminada e de chapas de madeira compensada, prensada e aglomerada & 0,0055 & 0,0219 & 0,0164 & 0,0327 & $-0,0266$ & 0,0033 & 0,0273 & 0,0240 & 0,0412 & $-0,0028$ \\
\hline 20222 & Fabric. de esquad. de madeira, de casas de mad. pré-fabric., estrut. de mad. e art. de carpint. & 0,0025 & 0,0119 & 0,0094 & 0,0205 & $-0,0335$ & 0,0017 & 0,0135 & 0,0118 & 0,0212 & $-0,0151$ \\
\hline 20230 & Fabricação de artefatos de tanoaria e embalagens de madeira & 0,0189 & 0,0510 & 0,0321 & 0,0399 & $-0,0106$ & 0,0065 & 0,0294 & 0,0229 & 0,0106 & $-0,0047$ \\
\hline 20290 & Fabric. de artefatos diversos de madeira, palha, cortica e material & 0,0032 & 0,0305 & 0,0274 & 0,0061 & $-0,0147$ & 0,0028 & 0,0203 & 0,0175 & 0,0141 & $-0,0092$ \\
\hline 21105 & Fabricação de celulose e outras pastas para a fabricação de papel & 0,0491 & 0,0640 & 0,0149 & 0,0306 & $-0,0283$ & 0,0379 & 0,0573 & 0,0194 & 0,0349 & $-0,0079$ \\
\hline 21210 & Fabricação de papel & 0,0160 & 0,0445 & 0,0286 & 0,0140 & $-0,0144$ & 0,0128 & 0,0291 & 0,0163 & 0,0160 & $-0,0117$ \\
\hline 21229 & Fabricação de papelão liso, cartolina e cartão & 0,0348 & 0,1319 & 0,0971 & 0,0669 & 0,0615 & 0,0305 & 0,0664 & 0,0359 & 0,0386 & 0,0098 \\
\hline 21318 & Fabricação de embalagens de papel & 0,0104 & 0,1102 & 0,0998 & 0,0150 & 0,0608 & 0,0099 & 0,0514 & 0,0415 & 0,0016 & 0,0147 \\
\hline 21326 & Fabric. de embalagens de papelão - inclusive a Fabric. de papelão & 0,0096 & 0,0478 & 0,0381 & 0,0072 & $-0,0045$ & 0,0089 & 0,0354 & 0,0264 & 0,0062 & $-0,0012$ \\
\hline 21415 & Fabric. de artefatos de papel, papelão, cartolina e cartão para escritório & 0,0156 & 0,2048 & 0,1893 & 0,0627 & 0,1565 & 0,0081 & 0,0645 & 0,0563 & 0,0068 & 0,0298 \\
\hline 21423 & Fabricação de fitas e formulários contínuos - impressos ou não & 0,0563 & 0,0911 & 0,0347 & $-0,0056$ & $-0,0061$ & 0,0179 & 0,0704 & 0,0525 & 0,0324 & 0,0266 \\
\hline 21490 & Fabric. de outros artefatos de pastas, papel, papelão, cartolina e cartão & 0,0082 & 0,1580 & 0,1498 & 0,0403 & 0,1132 & 0,0058 & 0,0715 & 0,0657 & 0,0132 & 0,0397 \\
\hline 22110 & Edição; edição e impressão de jornais & 0,0142 & 0,0474 & 0,0332 & $-0,0056$ & $-0,0087$ & 0,0097 & 0,0496 & 0,0399 & $-0,0020$ & 0,0139 \\
\hline 22128 & Edição; edição e impressão de revistas & 0,0493 & 0,6145 & 0,5651 & 0,3547 & 0,5779 & 0,0541 & 0,5153 & 0,4612 & 0,3133 & 0,4738 \\
\hline 22136 & Edição; edição e impressão de livros & 0,0162 & 0,3708 & 0,3546 & 0,1751 & 0,3326 & 0,0074 & 0,2550 & 0,2476 & 0,1313 & 0,2288 \\
\hline 22144 & Edição de discos, fitas e outros materiais gravados & 0,1725 & 0,2676 & 0,0951 & 0,0217 & 0,0763 & 0,0415 & 0,2435 & 0,2020 & 0,1100 & 0,1898 \\
\hline 22195 & Ediçãa; edição e impressão de outros produtos gráficos & 0,0040 & 0,0756 & 0,0716 & 0,0074 & 0,0316 & 0,0033 & 0,0859 & 0,0826 & 0,0198 & 0,0581 \\
\hline 22217 & Impressão de jornais, revistas e livros & 0,0287 & 0,1215 & 0,0928 & 0,0136 & 0,0552 & 0,0159 & 0,0999 & 0,0840 & 0,0166 & 0,0594 \\
\hline 22225 & Serv. de impressão de material escolar e de material para usos industrial e comercial & 0,0055 & 0,0895 & 0,0839 & 0,0100 & 0,0448 & 0,0031 & 0,0442 & 0,0411 & 0,0027 & 0,0152 \\
\hline 22292 & Execução de outros serviços gráficos & 0,0030 & 0,1261 & 0,1231 & 0,0285 & 0,0859 & 0,0020 & 0,0877 & 0,0857 & 0,0214 & 0,0612 \\
\hline 22314 & Reprodução de discos e fitas & 0,0539 & 0,3509 & 0,2970 & 0,1405 & 0,2868 & 0,0634 & 0,2467 & 0,1832 & 0,0867 & 0,1756 \\
\hline 22322 & Reprodução de fitas de vídeos & 0,0647 & 0,3749 & 0,3102 & 0,1376 & 0,3043 & 0,1954 & 0,3608 & 0,1654 & 0,2111 & 0,1870 \\
\hline 22330 & Reprodução de filmes & 0,0723 & 0,1808 & 0,1086 & 0,0356 & 0,0780 & 0,0237 & 0,0752 & 0,0515 & 0,0024 & 0,0264 \\
\hline 22349 & Reprodução de programas de informática em disquetes e fitas & 0,0479 & 0,2023 & 0,1544 & 0,0327 & 0,1271 & 0,0129 & 0,1735 & 0,1606 & 0,0687 & 0,1430 \\
\hline 23108 & Coquerias & 0,2702 & 0,3247 & 0,0545 & $-0,1393$ & 0,0404 & 0,1269 & 0,8449 & 0,7181 & 0,9531 & 0,8990 \\
\hline 23205 & Refino de petróleo & 0,0656 & 0,0841 & 0,0185 & $-0,0009$ & $-0,0236$ & 0,1582 & 0,1965 & 0,0383 & 0,0504 & 0,0191 \\
\hline 23302 & Elaboração de combustíveis nucleares & 0,5822 & 0,5822 & 0,0000 & 0,8251 & $-0,0449$ & 0,2614 & 0,2614 & 0,0000 & 0,0281 & $-0,0288$ \\
\hline 23400 & Produção de álcool & 0,0141 & 0,0215 & 0,0074 & 0,0502 & $-0,0370$ & 0,0170 & 0,0279 & 0,0108 & 0,0373 & $-0,0174$ \\
\hline 24112 & Fabricação de cloro e alcalis & 0,0824 & 0,1013 & 0,0189 & 0,0434 & $-0,0230$ & 0,1512 & 0,1646 & 0,0134 & 0,0357 & $-0,0120$ \\
\hline 24120 & Fabricação de Intermediários para fertilizantes & 0,0362 & 0,0999 & 0,0637 & $-0,0094$ & 0,0255 & 0,1425 & 0,2399 & 0,0973 & 0,1221 & 0,0916 \\
\hline 24139 & Fabricação de fertilizantes fosfatados, nitrogenados e potássicos & 0,0123 & 0,0466 & 0,0342 & 0,0310 & $-0,0086$ & 0,0114 & 0,0363 & 0,0249 & 0,0320 & $-0,0028$ \\
\hline 24147 & Fabricação de gases industriais & 0,0230 & 0,0910 & 0,0679 & 0,0266 & 0,0281 & 0,0121 & 0,0730 & 0,0609 & 0,0160 & 0,0351 \\
\hline 24198 & Fabricação de outros produtos inorgânicos & 0,0597 & 0,0716 & 0,0119 & 0,0101 & $-0,0315$ & 0,0342 & 0,0590 & 0,0247 & 0,0193 & $-0,0022$ \\
\hline 24210 & Fabricação de produtos petroquímicos básicos & 0,0383 & 0,2684 & 0,2301 & 0,1842 & 0,2071 & 0,0653 & 0,2124 & 0,1471 & 0,1138 & 0,1350 \\
\hline 24228 & Fabricação de intermediários para resinas e fibras & 0,0359 & 0,1392 & 0,1032 & 0,0297 & 0,0687 & 0,0448 & 0,1036 & 0,0588 & 0,0489 & 0,0356 \\
\hline 24295 & Fabricação de outros produtos químicos orgânicos & 0,0253 & 0,0716 & 0,0463 & 0,0046 & 0,0051 & 0,0195 & 0,0540 & 0,0346 & 0,0076 & 0,0076 \\
\hline 24317 & Fabricação de resinas termoplásticas & 0,0619 & 0,2536 & 0,1917 & 0,0554 & 0,1709 & 0,0236 & 0,1358 & 0,1122 & 0,0532 & 0,0903 \\
\hline 24325 & Fabricação de resinas termofixas & 0,1230 & 0,1687 & 0,0458 & 0,0032 & 0,0112 & 0,1391 & 0,1569 & 0,0178 & 0,0234 & $-0,0066$ \\
\hline 24333 & Fabricação de elastómeros & 0,0748 & 0,1814 & 0,1065 & 0,0186 & 0,0823 & 0,1188 & 0,1443 & 0,0254 & $-0,0267$ & 0,0036 \\
\hline 24414 & Fabricação de fibras, fios, cabos e filamentos contínuos artificiais & 0,1239 & 0,2037 & 0,0798 & 0,0380 & 0,0522 & 0,3723 & 0,4923 & 0,1200 & $-0,0680$ & 0,1781 \\
\hline
\end{tabular}

(continua) 
MEDIDAS DE CONCENTRAÇÃO PARA A INDÚSTRIA DE TRANSFORMAÇÃO, ADOTANDO COMO UNIDADE DE ÁREA AS MICRORREGIÓES DO IBGE, SEGUNDO A CLASSIFICAÇÃO CNAE COM 4 DÍGITOS. BRASIL - 1995/ 2001 - (continuação)

\begin{tabular}{|c|c|c|c|c|c|c|c|c|c|c|c|}
\hline \multirow{2}{*}{ Código } & \multirow{2}{*}{ Descrição do setor } & \multicolumn{5}{|c|}{1995} & \multicolumn{5}{|c|}{2001} \\
\hline & & $\mathrm{M}$ & $\mathrm{F}$ & $\alpha$ & $\gamma \mathrm{eg}$ & $\gamma_{\mathrm{ms}}$ & M & $\mathrm{F}$ & $\alpha$ & $\gamma_{\mathrm{eg}}$ & $\gamma_{\mathrm{ms}}$ \\
\hline 24422 & Fabricação de fibras, fios, cabos e filamentos contínuos sintéticos & 0,0900 & 0,1374 & 0,0475 & $-0,0225$ & 0,0107 & 0,0830 & 0,2958 & 0,2128 & 0,2459 & 0,2153 \\
\hline 24511 & Fabricação de produtos farmoquímicos & 0,0282 & 0,1471 & 0,1189 & 0,0471 & 0,0835 & 0,0317 & 0,1369 & 0,1052 & 0,0502 & 0,0835 \\
\hline 24520 & Fabricação de medicamentos para uso humano & 0,0087 & 0,2058 & 0,1972 & 0,0679 & 0,1636 & 0,0071 & 0,1232 & 0,1161 & 0,0401 & 0,0920 \\
\hline 24538 & Fabricação de medicamentos para uso veterinário & 0,0635 & 0,1027 & 0,0392 & 0,0241 & $-0,0007$ & 0,0220 & 0,0647 & 0,0427 & 0,0013 & 0,0164 \\
\hline 24546 & Fabric. de materiais para usos médicos, hospitalares e odontológicos & 0,0571 & 0,1666 & 0,1096 & 0,0617 & 0,0771 & 0,0368 & 0,1174 & 0,0806 & 0,0177 & 0,0577 \\
\hline 24619 & Fabricação de inseticidas & 0,0692 & 0,1102 & 0,0410 & $-0,0356$ & 0,0023 & 0,1168 & 0,1308 & 0,0140 & 0,0099 & $-0,0120$ \\
\hline 24627 & Fabricação de fungicidas & 0,2222 & 0,2222 & 0,0000 & $-0,8364$ & $-0,0449$ & 0,0500 & 0,1519 & 0,1019 & 0,1143 & 0,1051 \\
\hline 24635 & Fabricação de herbicidas & 0,0767 & 0,1437 & 0,0670 & 0,0673 & 0,0361 & 0,1993 & 0,2580 & 0,0586 & 0,0995 & 0,0573 \\
\hline 24694 & Fabricação de outros defensivos agrícolas & 0,0424 & 0,0916 & 0,0492 & $-0,0077$ & 0,0099 & 0,0672 & 0,1376 & 0,0704 & 0,0102 & 0,0504 \\
\hline 24716 & Fabricação de sabões, sabonetes e detergentes sintéticos & 0,0170 & 0,0607 & 0,0437 & 0,0052 & 0,0019 & 0,0128 & 0,0425 & 0,0297 & 0,0033 & 0,0026 \\
\hline 24724 & Fabricação de produtos de limpeza e polimento & 0,0340 & 0,1233 & 0,0892 & $-0,0031$ & 0,0518 & 0,0177 & 0,0629 & 0,0452 & $-0,0006$ & 0,0192 \\
\hline 24732 & Fabricação de artigos de perfumaria e cosméticos & 0,0264 & 0,2190 & 0,1926 & 0,0625 & 0,1625 & 0,0115 & 0,1211 & 0,1097 & 0,0358 & 0,0862 \\
\hline 24813 & Fabricação de tintas, vernizes, esmaltes e lacas & 0,0128 & 0,1599 & 0,1471 & 0,0365 & 0,1111 & 0,0118 & 0,1108 & 0,0990 & 0,0255 & 0,0748 \\
\hline 24821 & Fabricação de tintas de impressão & 0,0605 & 0,1443 & 0,0838 & $-0,0035$ & 0,0513 & 0,0461 & 0,1839 & 0,1378 & 0,0509 & 0,1224 \\
\hline 24830 & Fabricação de impermeabilizantes, solventes e produtos afins & 0,0305 & 0,1634 & 0,1329 & 0,0226 & 0,0996 & 0,0342 & 0,1155 & 0,0813 & 0,0072 & 0,0584 \\
\hline 24910 & Fabricação de adesivos e selantes & 0,0439 & 0,1619 & 0,1181 & 0,0278 & 0,0852 & 0,0331 & 0,0942 & 0,0611 & 0,0057 & 0,0367 \\
\hline 24929 & Fabricação de explosivos & 0,0466 & 0,1761 & 0,1295 & 0,1585 & 0,0985 & 0,0260 & 0,2274 & 0,2014 & 0,2225 & 0,1859 \\
\hline 24937 & Fabricação de catalisadores & 0,5921 & 0,5935 & 0,0013 & $-0,1152$ & $-0,0402$ & 0,2770 & 0,3416 & 0,0646 & 0,0376 & 0,0823 \\
\hline 24945 & Fabricação de aditivos de uso industrial & 0,0358 & 0,1005 & 0,0647 & 0,0281 & 0,0264 & 0,0217 & 0,1031 & 0,0814 & 0,0185 & 0,0578 \\
\hline 24953 & Fabric. de chapas, filmes, papéis e outros mat.s e prod. químicos para fotografia & 0,1026 & 0,2190 & 0,1165 & 0,0364 & 0,0919 & 0,1151 & 0,2714 & 0,1563 & 0,1354 & 0,1577 \\
\hline 24961 & Fabricação de discos e fitas virgens & 0,3038 & 0,4381 & 0,1344 & 0,2088 & 0,1870 & 0,4515 & 0,4566 & 0,0051 & $-0,0042$ & $-0,0159$ \\
\hline 24996 & Fabric. de outros produtos químicos não especificados ou não classificados & 0,0045 & 0,1169 & 0,1124 & 0,0217 & 0,0746 & 0,0029 & 0,0667 & 0,0638 & 0,0116 & 0,0384 \\
\hline 25119 & Fabricação de pneumáticos e de câmaras-de-ar & 0,1000 & 0,2652 & 0,1652 & 0,0153 & 0,1485 & 0,0807 & 0,2401 & 0,1594 & 0,0496 & 0,1514 \\
\hline 25127 & Recondicionamento de pneumáticos & 0,0011 & 0,0145 & 0,0134 & 0,0107 & $-0,0297$ & 0,0013 & 0,0125 & 0,0112 & 0,0071 & $-0,0162$ \\
\hline 25194 & Fabricação de artefatos diversos de borracha & 0,0062 & 0,1567 & 0,1504 & 0,0440 & 0,1145 & 0,0057 & 0,0802 & 0,0745 & 0,0197 & 0,0495 \\
\hline 25216 & Fabricação de laminados planos e tubulares plásticos & 0,0242 & 0,1129 & 0,0887 & 0,0137 & 0,0505 & 0,0231 & 0,0596 & 0,0365 & $-0,0032$ & 0,0098 \\
\hline 25224 & Fabricação de embalagem de plástica & 0,0031 & 0,0961 & 0,0930 & 0,0131 & 0,0538 & 0,0019 & 0,0527 & 0,0508 & 0,0063 & 0,0250 \\
\hline 25291 & Fabricação de artefatos diversos de plástico & 0,0016 & 0,1169 & 0,1153 & 0,0236 & 0,0775 & 0,0010 & 0,0688 & 0,0678 & 0,0125 & 0,0427 \\
\hline 26115 & Fabricação de vidro plano e de segurança & 0,0338 & 0,2821 & 0,2483 & 0,1156 & 0,2270 & 0,0290 & 0,1437 & 0,1147 & 0,0454 & 0,0937 \\
\hline 26123 & Fabricação de vasilhames de vidro & 0,1447 & 0,4157 & 0,2710 & 0,0906 & 0,2910 & 0,0916 & 0,1915 & 0,0999 & 0,0176 & 0,0872 \\
\hline 26190 & Fabricação de artigos de vidro & 0,0265 & 0,1527 & 0,1263 & 0,0224 & 0,0911 & 0,0354 & 0,1513 & 0,1159 & 0,0301 & 0,0952 \\
\hline 26204 & Fabricação de cimento & 0,0120 & 0,0299 & 0,0179 & 0,0266 & $-0,0259$ & 0,0146 & 0,0267 & 0,0121 & 0,0167 & $-0,0161$ \\
\hline 26301 & Fabric. de artefatos de concreto, cimento, fibrocimento, gesso e estuque & 0,0015 & 0,0214 & 0,0200 & 0,0134 & $-0,0223$ & 0,0007 & 0,0134 & 0,0127 & 0,0080 & $-0,0140$ \\
\hline 26417 & Fabric. de produtos cerâmicos não-refratarios para uso estrutural & 0,0014 & 0,0116 & 0,0102 & 0,0348 & $-0,0326$ & 0,0007 & 0,0102 & 0,0095 & 0,0261 & $-0,0174$ \\
\hline 26425 & Fabricação de produtos cerâmicos refratários & 0,0188 & 0,0360 & 0,0172 & 0,0133 & $-0,0262$ & 0,0251 & 0,0584 & 0,0333 & 0,0343 & 0,0065 \\
\hline 26492 & Fabricação de produtos cerâmicos não-refratários para usos diversos & 0,0073 & 0,0335 & 0,0262 & 0,0460 & $-0,0161$ & 0,0084 & 0,0306 & 0,0222 & 0,0264 & $-0,0049$ \\
\hline 26913 & Britamento, aparelhamento e outros trab. em pedras & 0,0015 & 0,0418 & 0,0403 & 0,0411 & $-0,0013$ & 0,0006 & 0,0458 & 0,0453 & 0,0470 & 0,0194 \\
\hline 26921 & Fabricação de cal virgem, cal hidratada e gesso & 0,0103 & 0,0880 & 0,0777 & 0,1028 & 0,0374 & 0,0086 & 0,1073 & 0,0986 & 0,1076 & 0,0738 \\
\hline 26999 & Fabricação de outros produtos de minerais não-metálicos & 0,0112 & 0,0409 & 0,0297 & 0,0141 & $-0,0124$ & 0,0052 & 0,0365 & 0,0312 & 0,0141 & 0,0045 \\
\hline 27111 & Produção de laminados planos de aço & 0,1916 & 0,2615 & 0,0699 & 0,1254 & 0,0461 & 0,1724 & 0,2455 & 0,0731 & 0,1071 & 0,0628 \\
\hline 27120 & Produção de laminados não-planos de aço & 0,0887 & 0,1117 & 0,0230 & 0,0091 & $-0,0183$ & 0,0460 & 0,0571 & 0,0111 & $-0,0036$ & $-0,0166$ \\
\hline 27219 & Produção de gusa & 0,0131 & 0,1652 & 0,1521 & 0,1972 & 0,1177 & 0,0122 & 0,1520 & 0,1399 & 0,1677 & 0,1183 \\
\hline 27227 & Produção de ferro, aco e ferro-ligas em formas primárias e semi-acabados & 0,0357 & 0,0603 & 0,0246 & 0,0346 & $-0,0181$ & 0,0253 & 0,0515 & 0,0262 & 0,0200 & $-0,0010$ \\
\hline 27294 & Produção de relaminados, trefilados e retrefilados de aço - exclusive tubos & 0,0227 & 0,2295 & 0,2069 & 0,0758 & 0,1774 & 0,0283 & 0,2030 & 0,1748 & 0,0819 & 0,1570 \\
\hline 27316 & Fabricação de tubos de aço com costura & 0,0358 & 0,0954 & 0,0596 & 0,0115 & 0,0207 & 0,0400 & 0,0781 & 0,0381 & $-0,0064$ & 0,0124 \\
\hline 27391 & Fabricação de outros tubos de ferro e aço & 0,3400 & 0,3749 & 0,0350 & 0,0071 & 0,0110 & 0,3280 & 0,3797 & 0,0517 & 0,0415 & 0,0512 \\
\hline 27413 & Metalurgia do alumínio e suas ligas & 0,0547 & 0,0857 & 0,0309 & 0,0133 & $-0,0103$ & 0,0550 & 0,0882 & 0,0332 & 0,0205 & 0,0076 \\
\hline 27421 & Metalurgia dos metais preciosos & 0,0318 & 0,1806 & 0,1488 & 0,0402 & 0,1178 & 0,0249 & 0,1281 & 0,1032 & 0,0444 & 0,0817 \\
\hline 27499 & Metalurgia de outros metais não-ferrosos e suas ligas & 0,0170 & 0,1442 & 0,1273 & 0,0276 & 0,0911 & 0,0277 & 0,1192 & 0,0916 & 0,0248 & 0,0687 \\
\hline 27510 & Fabricação de peças fundidas de ferro e aço & 0,0129 & 0,0642 & 0,0513 & 0,0136 & 0,0108 & 0,0197 & 0,0541 & 0,0344 & 0,0186 & 0,0086 \\
\hline 27529 & Fabricação de peças fundidas de metais nao-ferrosos e suas ligas & 0,0080 & 0,1541 & 0,1461 & 0,0406 & 0,1100 & 0,0088 & 0,0817 & 0,0730 & 0,0147 & 0,0478 \\
\hline 28118 & Fabric. de estrut. metálicas para edifícios, pontes, torres de transm., andaimes e outros fins & 0,0225 & 0,0503 & 0,0278 & 0,0178 & $-0,0141$ & 0,0131 & 0,0328 & 0,0196 & 0,0180 & $-0,0071$ \\
\hline 28126 & Fabricação de esquadrias de metal & 0,0045 & 0,0462 & 0,0417 & 0,0070 & 0,0005 & 0,0027 & 0,0220 & 0,0193 & 0,0032 & $-0,0072$ \\
\hline 28134 & Fabricação de obras de caldeiraria pesada & 0,0249 & 0,0880 & 0,0631 & 0,0132 & 0,0231 & 0,0342 & 0,0536 & 0,0194 & 0,0155 & $-0,0080$ \\
\hline 28215 & Fabric. de tanques, reservatórios metálicos e caldeiras para aquecimento central & 0,0231 & 0,0631 & 0,0401 & 0,0076 & $-0,0019$ & 0,0097 & 0,0239 & 0,0143 & 0,0116 & $-0,0139$ \\
\hline
\end{tabular}

(continua) 
MEDIDAS DE CONCENTRAÇÃO PARA A INDÚSTRIA DE TRANSFORMAÇÃO, ADOTANDO COMO UNIDADE DE ÁREA AS MICRORREGIÓOES DO IBGE, SEGUNDO A CLASSIFICAÇÃO CNAE COM 4 DÍGITOS. BRASIL - 1995/ 2001 - (continuação)

\begin{tabular}{|c|c|c|c|c|c|c|c|c|c|c|c|}
\hline \multirow{2}{*}{ Código } & \multirow{2}{*}{ Descrição do setor } & \multicolumn{5}{|c|}{1995} & \multicolumn{5}{|c|}{2001} \\
\hline & & $M$ & $F$ & $\alpha$ & $\gamma \mathrm{eg}$ & $\gamma \mathrm{ms}$ & $M$ & $F$ & $\alpha$ & $\gamma e g$ & $\gamma \mathrm{ms}$ \\
\hline 28223 & Fabric. de caldeiras gerad. de vapor - exclusive para aquecimento central e para veículos & 0,0637 & 0,1107 & 0,0470 & 0,0054 & 0,0087 & 0,0882 & 0,1492 & 0,0610 & 0,0525 & $\overline{0,0412}$ \\
\hline 28312 & Produção de forjados de aço & 0,0494 & 0,1236 & 0,0742 & 0,0288 & 0,0373 & 0,0875 & 0,1845 & 0,0969 & 0,0921 & 0,0813 \\
\hline 28320 & Produção de forjados de metais nao-ferrosos e suas ligas & 0,2191 & 0,3511 & 0,1321 & 0,0564 & 0,1335 & 0,0205 & 0,1242 & 0,1037 & 0,0280 & 0,0808 \\
\hline 28339 & Fabricação de artefatos estampados de metal & 0,0084 & 0,1719 & 0,1635 & 0,0502 & 0,1282 & 0,0065 & 0,1071 & 0,1006 & 0,0304 & 0,0764 \\
\hline 28347 & Metalurgia do pó & 0,0693 & 0,1348 & 0,0655 & $-0,0346$ & 0,0307 & 0,0544 & 0,1080 & 0,0536 & $-0,0120$ & 0,0310 \\
\hline 28398 & Têmpera, cementação e tratamento térmico do aço, serv. de usinagem, galvanot. e solda & 0,0019 & 0,2687 & 0,2668 & 0,1128 & 0,2357 & 0,0011 & 0,1039 & 0,1029 & 0,0311 & 0,0786 \\
\hline 28410 & Fabricação de artigos de cutelaria & 0,0878 & 0,2550 & 0,1672 & 0,1661 & 0,1479 & 0,0952 & 0,2347 & 0,1395 & 0,1345 & 0,1308 \\
\hline 28428 & Fabricação de artigos de serralheria - exclusive esquadrias & 0,0010 & 0,0443 & 0,0433 & 0,0050 & 0,0020 & 0,0013 & 0,0268 & 0,0254 & 0,0012 & $-0,0010$ \\
\hline 28436 & Fabricação de ferramentas manuais & 0,0252 & 0,1820 & 0,1568 & 0,0571 & 0,1239 & 0,0188 & 0,1195 & 0,1007 & 0,0366 & 0,0771 \\
\hline 28916 & Fabricação de embalagens metálicas & 0,0208 & 0,1422 & 0,1215 & 0,0197 & 0,0855 & 0,0223 & 0,1137 & 0,0914 & 0,0190 & 0,0679 \\
\hline 28924 & Fabricação de artefatos de trefilados & 0,0262 & 0,1549 & 0,1287 & 0,0295 & 0,0936 & 0,0078 & 0,1131 & 0,1053 & 0,0362 & 0,0814 \\
\hline 28932 & Fabric. de artigos de funilaria e de artigos de metal para usos doméstico e pessoal & 0,0138 & 0,1098 & 0,0960 & 0,0228 & 0,0578 & 0,0049 & 0,0422 & 0,0373 & 0,0034 & 0,0109 \\
\hline 28991 & Fabricação de outros produtos elaborados de metal & 0,0014 & 0,1343 & 0,1330 & 0,0311 & 0,0960 & 0,0011 & 0,0595 & 0,0584 & 0,0085 & 0,0330 \\
\hline 29114 & Fabric. de motores estacion. de combustão interna, turbinas e outras máqu. motrizes não elétricas & 0,1043 & 0,1332 & 0,0289 & 0,0209 & $-0,0107$ & 0,1063 & 0,2263 & 0,1200 & 0,1107 & 0,1108 \\
\hline 29122 & Fabricação de bombas e carneiros hidraulicos & 0,0184 & 0,0694 & 0,0510 & 0,0137 & 0,0096 & 0,0144 & 0,0539 & 0,0394 & 0,0086 & 0,0126 \\
\hline 29130 & Fabricação de válvulas, torneiras e registros & 0,0191 & 0,2132 & 0,1941 & 0,0640 & 0,1630 & 0,0322 & 0,1779 & 0,1458 & 0,0549 & 0,1269 \\
\hline 29149 & Fabricação de compressores & 0,2793 & 0,3437 & 0,0644 & 0,1258 & 0,0509 & 0,4161 & 0,6517 & 0,2356 & 0,4310 & 0,3983 \\
\hline 29157 & Fabricação de equipamentos de transmissão para fins industriais - inclusive rolamentos & 0,0768 & 0,1974 & 0,1206 & 0,0106 & 0,0927 & 0,0485 & 0,0918 & 0,0434 & 0,0062 & 0,0184 \\
\hline 29211 & Fabricação de fornos industriais, aparelhos e equipamentos não-elétricos para instalações térmicas & 0,0350 & 0,0895 & 0,0545 & 0,0109 & 0,0149 & 0,0226 & 0,0709 & 0,0483 & 0,0011 & 0,0225 \\
\hline 29220 & Fabricação de estufas e fornos elétricos para fins industriais & 0,0516 & 0,2616 & 0,2100 & 0,0602 & 0,1887 & 0,0414 & 0,1876 & 0,1462 & 0,0437 & 0,1304 \\
\hline 29238 & Fabricação de máquinas, equipamentos e aparelhos para transp. e elevação de cargas e pessoas & 0,0138 & 0,1471 & 0,1333 & 0,0272 & 0,0967 & 0,0074 & 0,0883 & 0,0808 & 0,0171 & 0,0552 \\
\hline 29246 & Fabricação de máquinas e aparelhos de refrigeração e ventilaçao de uso industrial & 0,0090 & 0,1171 & 0,1081 & 0,0173 & 0,0693 & 0,0048 & 0,0705 & 0,0657 & 0,0105 & 0,0396 \\
\hline 29254 & Fabricação de aparelhos de ar condicionado & 0,0834 & 0,1721 & 0,0887 & 0,0256 & 0,0574 & 0,1186 & 0,1708 & 0,0522 & $-0,0052$ & 0,0330 \\
\hline 29297 & Fabricação de outras máquinas e equipamentos de uso geral & 0,0047 & 0,1168 & 0,1121 & 0,0214 & 0,0740 & 0,0020 & 0,0658 & 0,0639 & 0,0111 & 0,0386 \\
\hline 29319 & Fabricação de máquinas e equipamentos para agricultura, avicultura e obteção de produtos animais & 0,0148 & 0,0393 & 0,0245 & 0,0512 & $-0,0183$ & 0,0110 & 0,0270 & 0,0161 & 0,0333 & $-0,0112$ \\
\hline 29327 & Fabricação de tratores agrícolas & 0,2007 & 0,2361 & 0,0354 & 0,0047 & 0,0040 & 0,2925 & 0,2975 & 0,0050 & $-0,0175$ & $-0,0213$ \\
\hline 29408 & Fabricação de máquinas-ferramenta & 0,0155 & 0,1593 & 0,1439 & 0,0443 & 0,1081 & 0,0141 & 0,1054 & 0,0912 & 0,0273 & 0,0669 \\
\hline 29513 & Fabricação de máquinas e equipamentos para a ind. de prospeccão e extração de petróleo & 0,0570 & 0,3842 & 0,3273 & 0,3250 & 0,3306 & 0,1177 & 0,2157 & 0,0980 & 0,1147 & 0,0883 \\
\hline 29521 & Fabricação de outras máquinas e equipamentos para a extração de minérios & 0,0347 & 0,1501 & 0,1154 & 0,1082 & 0,0812 & 0,0346 & 0,1297 & 0,0951 & 0,0745 & 0,0735 \\
\hline 29530 & Fabricação de tratores de esteira e tratores de uso na construção e mineração & 0,1521 & 0,2799 & 0,1278 & 0,2190 & 0,1364 & 0,3510 & 0,3532 & 0,0022 & 0,0267 & $-0,0252$ \\
\hline 29548 & Fabricação de máquinas e equipamentos de terraplanagem e pavimentação & 0,0638 & 0,1168 & 0,0530 & 0,0146 & 0,0154 & 0,1300 & 0,2405 & 0,1104 & 0,0974 & 0,1058 \\
\hline 29610 & Fabricação de máquinas para a ind. metalúrgica - exclusive máquinas-ferramenta & 0,0088 & 0,1451 & 0,1363 & 0,0360 & 0,0992 & 0,0283 & 0,1192 & 0,0910 & 0,0160 & 0,0678 \\
\hline 29629 & Fabricação de máquinas e equipamentos para as ind. alimentar, de bebida e fumo & 0,0203 & 0,1619 & 0,1416 & 0,0356 & 0,1068 & 0,0075 & 0,0585 & 0,0510 & 0,0135 & 0,0242 \\
\hline 29637 & Fabricação de máquinas e equipamentos para a indústria textil & 0,0348 & 0,1636 & 0,1288 & 0,0367 & 0,0955 & 0,0178 & 0,1083 & 0,0905 & 0,0257 & 0,0666 \\
\hline 29645 & Fabricação de máquinas e equipamentos para as ind. do vestuário e de couro e calçado & 0,0157 & 0,2222 & 0,2065 & 0,1495 & 0,1753 & 0,0465 & 0,3018 & 0,2553 & 0,2316 & 0,2479 \\
\hline 29653 & Fabric. de máquinas e equipamentos para as ind. de celulose, papel, papelão e artefatos & 0,1441 & 0,2598 & 0,1157 & $-0,0387$ & 0,0981 & 0,0839 & 0,1938 & 0,1099 & 0,0106 & 0,0958 \\
\hline 29696 & Fabricação de outras máquinas e equipamentos de uso específico & 0,0047 & 0,0821 & 0,0773 & 0,0115 & 0,0373 & 0,0038 & 0,0795 & 0,0758 & 0,0172 & 0,0507 \\
\hline 29718 & nuniçãao & 0,1541 & 0,3499 & 0,1958 & 0,2761 & 0,2294 & 0,0991 & 0,2635 & 0,1644 & 0,1262 & 0,1752 \\
\hline 29726 & ento bélico & 0,2038 & 0,3577 & 0,1540 & 0,2507 & 0,2013 & 0,2133 & 0,6219 & 0,4086 & 0,6147 & 0,5753 \\
\hline 29815 & avar e secar para uso doméstico & 0,0895 & 0,1661 & 0,0766 & $-0,0075$ & 0,0439 & 0,0599 & 0,1196 & 0,0596 & 0,0387 & 0,0370 \\
\hline 29890 & Fabricação de outros aparelhos eletrodomesticos & 0,0726 & 0,2162 & 0,1436 & 0,0215 & 0,1176 & 0,0469 & 0,2233 & 0,1763 & 0,0773 & 0,1625 \\
\hline 30113 & Fabric. de máqu. de escrever e calcular, copiadoras e outros equip. não-eletrônicos para escritório & 0,1124 & 0,1924 & 0,0800 & 0,0619 & 0,0519 & 0,2906 & 0,2914 & 0,0008 & 0,0238 & $-0,0276$ \\
\hline 30120 & Fabricação de máquinas de escrever e calcular, copiadoras e outros equipamentos eletrônicos & 0,0454 & 0,1989 & 0,1535 & 0,0725 & 0,1243 & 0,0439 & 0,0963 & 0,0524 & 0,0074 & 0,0285 \\
\hline 30210 & Fabricação de computadores & 0,0179 & 0,1533 & 0,1354 & 0,0380 & 0,1000 & 0,0223 & 0,1696 & 0,1473 & 0,0624 & 0,1269 \\
\hline 30228 & Fabric. de equipamentos periféricos para máquinas eletrônicas para tratamento de informações & 0,0172 & 0,2108 & 0,1936 & 0,0680 & 0,1619 & 0,0227 & 0,1242 & 0,1016 & 0,0288 & 0,0785 \\
\hline 31119 & Fabricação de geradores de corrente continua ou alternada & 0,1212 & 0,2466 & 0,1254 & 0,1309 & 0,1071 & 0,0944 & 0,1761 & 0,0817 & 0,0577 & 0,0655 \\
\hline 31127 & Fabric. de transformadores, indutores, conversores, sincronizadores e semelhantes & 0,0187 & 0,0917 & 0,0730 & 0,0104 & 0,0331 & 0,0163 & 0,0565 & 0,0402 & 0,0041 & 0,0134 \\
\hline 31135 & Fabricação de motores elétricos & 0,1029 & 0,3684 & 0,2656 & 0,3090 & 0,2674 & 0,1328 & 0,2679 & 0,1351 & 0,1335 & 0,1326 \\
\hline 31216 & Fabric. de subestações, quadros de comando, regulad. de voltagem e outros aparelhos e equip. & 0,0203 & 0,1475 & 0,1271 & 0,0184 & 0,0912 & 0,0200 & 0,0735 & 0,0534 & 0,0000 & 0,0275 \\
\hline 31224 & Fabric. de material eletrico para instalações em circuito de consumo & 0,0299 & 0,1944 & 0,1644 & 0,0536 & 0,1330 & 0,0255 & 0,1540 & 0,1285 & 0,0421 & 0,1075 \\
\hline 31305 & Fabricação de fios, cabos e condutores elétricos isolados & 0,0129 & 0,1179 & 0,1050 & 0,0189 & 0,0667 & 0,0115 & 0,0625 & 0,0510 & 0,0091 & 0,0245 \\
\hline 31410 & Fabric. de pilhas, baterias e acumuladores elétricos - exclusive para veículos & 0,1143 & 0,2354 & 0,1210 & 0,0335 & 0,1002 & 0,1387 & 0,1737 & 0,0350 & 0,0201 & 0,0142 \\
\hline 31429 & Fabricação de baterias e acumuladores para veículos & 0,0899 & 0,1190 & 0,0290 & 0,0385 & $-0,0113$ & 0,0842 & 0,1464 & 0,0621 & 0,0895 & 0,0416 \\
\hline 31518 & Fabricação de lampadas & 0,1692 & 0,2845 & 0,1153 & $-0,0174$ & 0,1066 & 0,1331 & 0,1996 & 0,0665 & $-0,0313$ & 0,0523 \\
\hline 31526 & Fabric. de luminárias e equipamentos de iluminação - exclusive para veículos & 0,0103 & 0,2929 & 0,2826 & 0,1282 & 0,2543 & 0,0049 & 0,1467 & 0,1418 & 0,0560 & 0,1181 \\
\hline
\end{tabular}

(continua) 
MEDIDAS DE CONCENTRAÇÃO PARA A INDÚSTRIA DE TRANSFORMAÇÃO, ADOTANDO COMO UNIDADE DE ÁREA AS MICRORREGIÕES DO IBGE, SEGUNDO A CLASSIFICAÇÃO CNAE COM 4 DÍGITOS. BRASIL - 1995/ 2001 - (continuação)

\begin{tabular}{|c|c|c|c|c|c|c|c|c|c|c|c|}
\hline \multirow{2}{*}{ Código } & \multirow{2}{*}{ Descrição do setor } & \multicolumn{5}{|c|}{1995} & \multicolumn{5}{|c|}{2001} \\
\hline & & $M$ & $F$ & $\alpha$ & $\gamma \mathrm{eg}$ & $\gamma \mathrm{ms}$ & $M$ & $F$ & $\alpha$ & $\gamma \mathrm{eg}$ & $\gamma \mathrm{ms}$ \\
\hline 31607 & Fabricação de material elétrico para veículos - exclusive baterias & 0,0685 & 0,1639 & 0,0954 & 0,0114 & 0,0629 & 0,0534 & 0,1084 & 0,0550 & 0,0131 & 0,0314 \\
\hline 31917 & Fabric. de eletrodos, contatos e outros art. de carvão e grafita para uso elétr., eletroímãs e isoladores & 0,0639 & 0,1481 & 0,0842 & 0,0079 & 0,0507 & 0,0949 & 0,1960 & 0,1011 & 0,0424 & 0,0887 \\
\hline 31925 & Fabricação de aparelhos e utensilios para sinalização e alarme & 0,0442 & 0,1746 & 0,1305 & 0,0300 & 0,0986 & 0,0197 & 0,0984 & 0,0787 & 0,0152 & 0,0543 \\
\hline 31992 & Fabricação de outros aparelhos ou equipamentos elétricos & 0,0140 & 0,1457 & 0,1317 & 0,0267 & 0,0957 & 0,0067 & 0,0849 & 0,0782 & 0,0188 & 0,0530 \\
\hline 32107 & Fabricação de material eletrônico básico & 0,0240 & 0,1380 & 0,1140 & 0,0313 & 0,0777 & 0,0130 & 0,1068 & 0,0938 & 0,0346 & 0,0696 \\
\hline 32212 & Fabric. de equip. transmiss. de rádio e televisão e de equipam. para estações telefônicas e etc & 0,0413 & 0,1990 & 0,1577 & 0,0566 & 0,1278 & 0,0485 & 0,1434 & 0,0949 & 0,0218 & 0,0743 \\
\hline 32220 & Fabric. de aparelhos telefônicos, sistemas de intercomunicaçao e semelhantes & 0,0435 & 0,1352 & 0,0917 & 0,0151 & 0,0558 & 0,0494 & 0,1080 & 0,0586 & 0,0210 & 0,0349 \\
\hline 32301 & Fabric. de apar. recep. de rádio e telev. e de reprodução, gravação ou amplificação de som e vídeo & 0,0453 & 0,3940 & 0,3487 & 0,3433 & 0,3383 & 0,0402 & 0,4398 & 0,3996 & 0,4030 & 0,4014 \\
\hline 33103 & Fabric. de apar. e instrum. para usos médico-hospitalares, odotológicos, de labor. e ortopédicos & 0,0107 & 0,1610 & 0,1504 & 0,0417 & 0,1148 & 0,0107 & 0,0827 & 0,0720 & 0,0157 & 0,0469 \\
\hline 33200 & Fabric. de apar. e instrum. de medida, teste e controle - exclusive equipam. para controle produtivo & 0,0251 & 0,1682 & 0,1431 & 0,0353 & 0,1091 & 0,0282 & 0,1392 & 0,1110 & 0,0325 & 0,0894 \\
\hline 33308 & Fabric. de máquinas, aparelhos e equipam. de sistemas eletrôn. dedicados a automação industrial & 0,0253 & 0,2031 & 0,1778 & 0,0593 & 0,1467 & 0,0210 & 0,1184 & 0,0974 & 0,0297 & 0,0739 \\
\hline 33405 & Fabric. de aparelhos, instrumentos e materiais ópticos, fotográficos e cinematográficos & 0,0194 & 0,0915 & 0,0721 & 0,0071 & 0,0327 & 0,0153 & 0,0820 & 0,0667 & 0,0149 & 0,0411 \\
\hline 33502 & Fabricação de cronometros e relógios & 0,0326 & 0,3293 & 0,2967 & 0,2453 & 0,2795 & 0,0362 & 0,3313 & 0,2950 & 0,2793 & 0,2902 \\
\hline 34100 & Fabricaçao de automoveis, camionetas e utilitarios & 0,1286 & 0,3717 & 0,2431 & 0,0991 & 0,2494 & 0,0884 & 0,2388 & 0,1503 & 0,0591 & 0,1438 \\
\hline 34207 & Fabricação de caminhões e ônibus & 0,2888 & 0,4644 & 0,1755 & $-0,0521$ & 0,2379 & 0,3357 & 0,5553 & 0,2196 & 0,0779 & 0,3323 \\
\hline 34312 & Fabricação de cabines, carrocerias e reboques para caminhão & 0,0150 & 0,0433 & 0,0284 & 0,0301 & $-0,0147$ & 0,0187 & 0,0478 & 0,0291 & 0,0287 & 0,0018 \\
\hline 34320 & Fabricação de carrocerias para ônibus & 0,1438 & 0,1644 & 0,0205 & 0,0462 & $-0,0188$ & 0,2107 & 0,2196 & 0,0089 & 0,0154 & $-0,0162$ \\
\hline 34398 & Fabricação de cabines, carrocerias e reboques para outros veiculos & 0,1560 & 0,2049 & 0,0488 & 0,0422 & 0,0158 & 0,1031 & 0,1281 & 0,0250 & 0,0155 & 0,0000 \\
\hline 34410 & Fabricação de peças e acessórios para o sistema motor & 0,0255 & 0,2279 & 0,2025 & 0,0766 & 0,1733 & 0,0395 & 0,1384 & 0,0989 & 0,0430 & 0,0776 \\
\hline 34428 & Fabric. de peças e acessórios para os sistemas de marcha e transmissão & 0,0697 & 0,1725 & 0,1028 & 0,0283 & 0,0722 & 0,0710 & 0,1545 & 0,0835 & 0,0181 & 0,0649 \\
\hline 34436 & Fabricação de peças e acessórios para o sistema de freios & 0,0627 & 0,1178 & 0,0550 & 0,0304 & 0,0171 & 0,0449 & 0,0967 & 0,0518 & 0,0352 & 0,0277 \\
\hline 34444 & Fabricação de peças e acessórios para o sistema de direção e suspensão & 0,0558 & 0,1998 & 0,1440 & 0,0272 & 0,1162 & 0,0339 & 0,1150 & 0,0811 & 0,0151 & 0,0585 \\
\hline 34495 & Fabric. de peças e acess. de metal para veiculos automotores não classificados em outra classe & 0,0080 & 0,2611 & 0,2531 & 0,1119 & 0,2229 & 0,0049 & 0,1220 & 0,1171 & 0,0425 & 0,0935 \\
\hline 34509 & Recondicionamento ou recuperação de motores para veículos automotores & 0,0015 & 0,0387 & 0,0372 & 0,0066 & $-0,0047$ & 0,0017 & 0,0221 & 0,0203 & 0,0036 & $-0,0069$ \\
\hline 35114 & Construção e reparação de embarcações e estruturas flutuantes & 0,1021 & 0,6372 & 0,5351 & 0,5678 & 0,5799 & 0,0475 & 0,2400 & 0,1925 & 0,1870 & 0,1800 \\
\hline 35122 & Construção e reparação de embarcações para esporte e lazer & 0,0428 & 0,2701 & 0,2273 & 0,1332 & 0,2052 & 0,0321 & 0,0946 & 0,0625 & 0,0268 & 0,0381 \\
\hline 35211 & Construção e montagem de locomotivas, vagões e outros materiais rodantes & 0,2936 & 0,4033 & 0,1097 & 0,1233 & 0,1391 & 0,2677 & 0,3616 & 0,0940 & $-0,0607$ & 0,1115 \\
\hline 35220 & Fabricação de peças e acessórios para veiculos ferroviários & 0,1116 & 0,2185 & 0,1069 & $-0,0098$ & 0,0846 & 0,1421 & 0,3067 & 0,1646 & 0,0732 & 0,1765 \\
\hline 35238 & Reparação de veículos ferroviários & 0,2701 & 0,3111 & 0,0410 & 0,1186 & 0,0158 & 0,1445 & 0,1921 & 0,0476 & 0,0528 & 0,0305 \\
\hline 35319 & Construção e montagem de aeronaves & 0,6070 & 0,6818 & 0,0748 & 0,3325 & 0,1691 & 0,5391 & 0,7130 & 0,1739 & 0,4500 & 0,3866 \\
\hline 35327 & Reparação de aeronaves & 0,2421 & 0,2841 & 0,0420 & 0,0377 & 0,0139 & 0,0644 & 0,1160 & 0,0516 & $-0,0188$ & 0,0286 \\
\hline 35912 & Fabricação de motocicletas & 0,2780 & 0,6424 & 0,3644 & 0,6139 & 0,5217 & 0,3960 & 0,6162 & 0,2201 & 0,4153 & 0,3666 \\
\hline 35920 & Fabricação de bicicletas e triciclos não-motorizados & 0,0707 & 0,3352 & 0,2645 & 0,1153 & 0,2540 & 0,0256 & 0,1033 & 0,0777 & 0,0281 & 0,0537 \\
\hline 35998 & Fabricação de outros equipamentos de transporte & 0,0216 & 0,0747 & 0,0531 & 0,0066 & 0,0121 & 0,0201 & 0,0972 & 0,0771 & 0,0174 & 0,0525 \\
\hline 36110 & Fabricação de móveis com predominância de madeira & 0,0007 & 0,0359 & 0,0352 & 0,0203 & $-0,0063$ & 0,0006 & 0,0219 & 0,0213 & 0,0173 & $-0,0051$ \\
\hline 36129 & Fabricação de móveis com predominância de metal & 0,0081 & 0,0586 & 0,0504 & 0,0281 & 0,0088 & 0,0052 & 0,0297 & 0,0245 & 0,0238 & $-0,0024$ \\
\hline 36145 & Fabricação de colchões & 0,0162 & 0,0615 & 0,0452 & 0,0020 & 0,0033 & 0,0152 & 0,0358 & 0,0206 & 0,0164 & $-0,0071$ \\
\hline 36919 & Lapidação de pedras preciosas e semi-preciosas, fabric. de artefatos de ourivesaria e joalheria & 0,0037 & 0,1156 & 0,1120 & 0,0390 & 0,0737 & 0,0024 & 0,0817 & 0,0793 & 0,0450 & 0,0540 \\
\hline 36927 & Fabricação de instrumentos musicais & 0,0678 & 0,1953 & 0,1275 & 0,0442 & 0,1000 & 0,0477 & 0,1077 & 0,0601 & 0,0296 & 0,0368 \\
\hline 36935 & Fabricação de artefatos para caça, pesca e esporte & 0,0181 & 0,1499 & 0,1318 & 0,0359 & 0,0966 & 0,0165 & 0,0848 & 0,0683 & 0,0130 & 0,0431 \\
\hline 36943 & Fabricação de brinquedos e de jogos recreativos & 0,0265 & 0,2030 & 0,1765 & 0,0668 & 0,1450 & 0,0216 & 0,1322 & 0,1106 & 0,0465 & 0,0878 \\
\hline 36951 & Fabricação de canetas, lápis, fitas impressoras para máquinas & 0,1584 & 0,3399 & 0,1815 & 0,1878 & 0,1834 & 0,0939 & 0,1891 & 0,0952 & 0,0772 & 0,0801 \\
\hline 36960 & Fabricação de aviamentos para costura & 0,0571 & 0,1968 & 0,1397 & 0,0275 & 0,1133 & 0,1386 & 0,1561 & 0,0175 & $-0,0124$ & $-0,0072$ \\
\hline 36978 & Fabricação de escovas, pinceis e vassouras & 0,0634 & 0,1243 & 0,0609 & 0,0302 & 0,0232 & 0,0388 & 0,0865 & 0,0478 & 0,0169 & 0,0225 \\
\hline 36994 & Fabricação de produtos diversos & 0,0028 & 0,0708 & 0,0680 & 0,0057 & 0,0278 & 0,0034 & 0,0506 & 0,0472 & 0,0069 & 0,0215 \\
\hline 37109 & Reciclagem de sucatas metálicas & 0,0191 & 0,0558 & 0,0368 & 0,0283 & $-0,0055$ & 0,0161 & 0,0400 & 0,0239 & 0,0208 & $-0,0037$ \\
\hline 37206 & Reciclagem de sucatas não-metálicas & 0,0108 & 0,0433 & 0,0326 & 0,0170 & $-0,0104$ & 0,0037 & 0,0205 & 0,0168 & 0,0062 & $-0,0111$ \\
\hline 40100 & Produção e Distribuição de Energia Elétrica & 0,0285 & 0,0460 & 0,0175 & $-0,0149$ & $-0,0245$ & 0,0202 & 0,0430 & 0,0227 & $-0,0060$ & $-0,0035$ \\
\hline 40207 & Produção e Distribuição de Gás através de Tubulações & 0,1062 & 0,4215 & 0,3153 & 0,1917 & 0,3289 & 0,1070 & 0,1546 & 0,0476 & $-0,0425$ & 0,0269 \\
\hline 40304 & Produção e Distribuição de Vapor e Água Quente & 0,0417 & 0,1392 & 0,0975 & 0,0336 & 0,0738 & 0,0981 & 0,1118 & 0,0137 & $-0,0580$ & $-0,0096$ \\
\hline 41009 & Captação, Tratamento e Distribuição de Água & 0,0186 & 0,0301 & 0,0115 & $-0,0044$ & $-0,0311$ & 0,0144 & 0,0251 & 0,0107 & $-0,0053$ & $-0,0162$ \\
\hline 55247 & Fomecimento de Comida Preparada & 0,0039 & 0,0861 & 0,0821 & 0,0148 & 0,0429 & 0,0055 & 0,0655 & 0,0601 & 0,0098 & 0,0350 \\
\hline 90000 & Limpeza Urbana e Esgoto & 0,0390 & 0,0946 & 0,0555 & $-0,0018$ & 0,0165 & 0,0258 & 0,0630 & 0,0372 & 0,0024 & 0,0116 \\
\hline 92118 & Produção de Filmes Cinematográficos e Fitas de Vídeo & 0,0110 & 0,3052 & 0,2942 & 0,1416 & 0,2668 & 0,0202 & 0,1436 & 0,1233 & 0,0544 & 0,1017 \\
\hline
\end{tabular}

Agradecemos a colaboração de Vera Marina, do Ministério do Trabalho, no sentido de permitir acesso aos microdados utilizados neste trabalho e ainda aos comentários de dois pareceristas anônimos a uma versão anterior do trabalho, mas os eventuais erros remanescentes são de nossa responsabilidade.

(Recebido em maio de 2004. Aceito para publicação em novembro de 2004). 